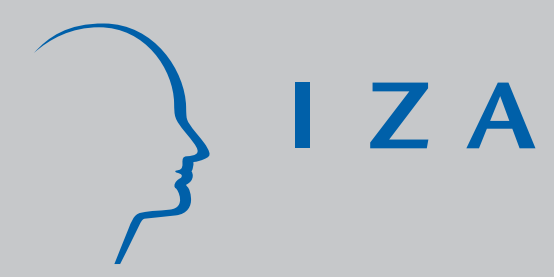

IZADP No. 2876

Intergenerational Mobility and Schooling Decisions in Germany and Italy: The Impact of Secondary School Tracks

Daniele Checchi

Luca Flabbi

J une 2007 


\title{
Intergenerational Mobility and Schooling Decisions in Germany and Italy: The Impact of Secondary School Tracks
}

\author{
Daniele Checchi \\ University of Milan, \\ CEPR and IZA
}

\section{Luca Flabbi}

Georgetown University,

CHILD and IZA

\section{Discussion Paper No. 2876 \\ June 2007}

\author{
IZA \\ P.O. Box 7240 \\ 53072 Bonn \\ Germany
}

Phone: +49-228-3894-0

Fax: +49-228-3894-180

E-mail: iza@iza.org

Any opinions expressed here are those of the author(s) and not those of the institute. Research disseminated by IZA may include views on policy, but the institute itself takes no institutional policy positions.

The Institute for the Study of Labor (IZA) in Bonn is a local and virtual international research center and a place of communication between science, politics and business. IZA is an independent nonprofit company supported by Deutsche Post World Net. The center is associated with the University of Bonn and offers a stimulating research environment through its research networks, research support, and visitors and doctoral programs. IZA engages in (i) original and internationally competitive research in all fields of labor economics, (ii) development of policy concepts, and (iii) dissemination of research results and concepts to the interested public.

IZA Discussion Papers often represent preliminary work and are circulated to encourage discussion. Citation of such a paper should account for its provisional character. A revised version may be available directly from the author. 


\begin{abstract}

\section{Intergenerational Mobility and Schooling Decisions in Germany and Italy: The Impact of Secondary School Tracks}

Intergenerational mobility in income and education is affected by the influence of parents on children's school choices. Our focus is on the role played by different school systems in reducing or magnifying the impact of parents on children's school choices and therefore on intergenerational mobility in general. We compare two apparently similar educational systems, Italy and Germany, to see how the common feature of separate tracks at Secondary School level may produce different impacts on children choices. Using data from a cross-country survey (PISA 2003), we study the impact of parental education on track choice, showing that the greater flexibility of the Italian system (where parents are free to choose the type of track) translates into greater dependence from parental background. These effects are reinforced when moving to post-secondary education, where the aspiration to go to college is affected not only by the school type but also (in the case of Italy only) by parental education. We then move to country-specific data sets (ISTAT 2001 for Italy and GSOEP 2001 and 2002 for Germany) to study the impact of family background on postsecondary school choices: we find this impact is greatly reduced when we control for secondary school tracks. Overall, we estimate large asymmetries by gender, with women's behavior more independent from family backgrounds than men's behavior.
\end{abstract}

\title{
JEL Classification: $\quad$ I2, J1
}

Keywords: $\quad$ secondary school tracks, education, intergenerational mobility

Corresponding author:

Daniele Checchi

Faculty of Political Science

University of Milan

Via Conservatorio 7

I-20122 Milano

Italy

E-mail: daniele.checchi@unimi.it

\footnotetext{
*We would like to thank for useful comments participants at the 2006 EEA Conference (Vienna), at the CEPR workshop (Uppsala), and at seminars the Universities of Modena, York and Turin.
} 


\section{Introduction}

One of the most well known fact in the analysis of educational choices is that parents matter. However there is less consensus about the channels responsible for such influence. In a survey on children's attainments, Haveman and Wolfe (1995) conclude that parental choices play a fundamental role on children's attainment and that recent research on the US finds much less mobility across generations that once though. A first explanation may reside in early childhood choices: Esping-Andersen (2004) shows that the impact of family backgrounds attenuates in countries characterized by extensive pre-school day care. A second partial explanation considers the possibility of borrowing constraints (Acemoglu and Pischke 2001). However, the recent literature seems to exclude borrowing constrains explanation as the main channel of the influence of parents on children's school choices even in countries, like the US, where the private cost of schooling is high. ${ }^{1}$ The role of parental choices is even more intriguing when considered in the European context, since most European countries, including Italy and Germany, are characterized by supposedly quite homogenous and egalitarian school system which nevertheless experience a low intergenerational mobility in schooling. ${ }^{2}$

While there are several other potential links across generations that may account for intergenerational persistence in education, in this paper we introduce an additional possibility, based on the institutional design of educational systems. An approach that studies in more details how institutional features of the school system impact the transmission of parents' decisions seems promising when we consider that crucial choices about amount and type of education are taken at a very different age in different educational systems. In comprehensive secondary school system (such as the US and UK) the fundamental decision about how much schooling to acquire is taken at the end of the secondary school level when individuals are about 18/19 years old. Given their older age, they are more likely to take decisions more independently from parental advice and pressure. On the contrary, in many European countries (namely Austria, Belgium, Germany, Italy, Ireland, the Netherlands, Slovakia, Spain and Turkey) a very crucial decision, the secondary school track, is taken at a much younger age (between 10 and 15 years old depending on the country). It seems quite intuitive that an early decision is more likely to be influenced by parents than a decision at a later stage in life, and therefore that a separate track system may

\footnotetext{
${ }^{1}$ For example, Keane and Wolpin 2001 show that even if borrowing constraints are estimated to be binding, their main impact is on consumption behaviour and not on schooling decision. Cameron and Heckman 1998 and 2001 estimate no impact of borrowing constraints once measures of ability are controlled for. Finally, Cameron and Taber 2004 using an innovative identification strategy also concludes that borrowing constraints are not important in schooling decisions.

${ }^{2}$ See Dustmann 2004 and Schnepf 2002 for Germany; Checchi 2003 and Flabbi 2001 for Italy. Using ECHP data, Comi 2004 provides estimates of intergenerational mobility in educational attainment, finding that Italy exhibits a quite low level of mobility. On the contrary, Chevalier, Denny and McMahon 2005 using IALS survey ranks Italy high in terms of intergenerational mobility in education, while Germany seems rather immobile. Unfortunately, Corak 2006 does not include Italy in international comparisons.
} 
lower intergenerational mobility in schooling. ${ }^{3}$ However, most of the impact depends on how the tracks are organized and on how the allocation of students to tracks is implemented.

In a recent paper, Hanushek and Wößmann (2005) have reviewed crosscountry empirical evidence on the effect of the age of first selection into school tracking, questioning a common view about the existence of a trade-off between equality and efficiency. According to their differences-in-differences analysis, countries characterized by early tracking exhibit greater inequality and lower mean performance in students' achievement tests, as measured at age 15. However, tracking can be based on different observables (student ability, parental education, family wealth, or even race or religion), generating major consequences in terms of (intertemporal) efficiency. Using different datasets, Brunello and Checchi (2007) show that the size of the tracking system (as measured by the age of the first selection into tracks and by the share of population attending vocational schools) reinforces the impact of family background on both educational choices (dropping out, attending college) and labour market outcomes (probability of employment, earnings), thus reinforcing intertemporal dependency. If we consider intergenerational mobility as one dimension of intertemporal efficiency (because more mobile societies are characterized by better allocation of talent and/or higher intertemporal welfare - Dardanoni 1993), then different tracking systems can in principle be ranked according to their impact on intergenerational mobility in educational levels. ${ }^{4}$

Following this idea, we analyze sorting over tracks generated in two countries characterized by early tracking: Italy and Germany. The German educational system sorts students into tracks at about age 10 (with some variation at Länder level, while the Italian system at about age 14 . While the institutional design of the two systems is rather similar (actually the Italian one was heavily inspired by Bismarck's schooling reforms), the Italian system is formally more flexible than the German one.

As a first finding, we confirm that the sorting rule is crucial to assess its relative impact on intergenerational mobility. Despite the earlier age of selection, we show that the educational career in Germany is less affected by parental education than in Italy. We argue that this may explain why Germany is usually ranked as a more mobile society than Italy in cross-country comparisons. ${ }^{5}$ As a second finding, we estimate strong gender asymmetries in Italy and small ones in Germany. Moreover, the Italy-Germany differential is much more pronounced on the male sample than on the female sample. As a third finding, we estimate

\footnotetext{
${ }^{3}$ This is the claim put forward by Dustmann 2004 for Germany.

${ }^{4}$ In addition, different degrees of intergenerational mobility in education are also correlated with (across cohorts) inequality measures of educational attainments. Using data for the adult population in 20 countries in the mid-nineties, Chevalier, Denny and McMahon (2005) show that intergenerational mobility and education inequality are positively correlated: as long as educational attainments of the sons are less dependent from the educational attainments of the corresponding fathers, this greater equality of opportunities translates into reduced differences in education within the same generation.

${ }^{5}$ See Grawe 2004 and Corak 2006. A direct comparison of Italy, US and Germany is in Checchi 1997.
} 
that the impact of family background on post-secondary school choices is greatly reduced when we control for secondary school tracks, in particular in Italy. Our main conclusion is that we should not only focus on differences between early and late tracking, as the previous literature has done, but also on the major differences within early tracking systems. An efficient early tracking system may actually increase intergenerational mobility while an inefficient early tracking may strongly magnify intergenerational persistence in education.

The paper is organized as follows. In the next section we provide some descriptive evidence on institutional differences between the school systems of Germany and Italy. In section 3, we introduce a simple model: two polar cases are considered, where student tracking is either based on perfectly observable ability or on family background (as predictor for unobservable ability); some implications in terms of efficiency and mobility are derived. We present the main empirical analysis in section 4, where we use microdata from a 2003 international survey on students' achievements coordinated by the OECD, the Programme for International Student Assessment (PISA), to assess the impact of family backgrounds on the tracks choice, comparing by gender and by country. In section 5 we use the same data to estimate the impact of family background on students' aspirations to proceed further in education and we use a different data source (two nationally representative samples of secondary school graduates) to evaluate the impact of parental education on actual tertiary school level choices. Section 6 concludes.

\section{Different Educational Systems and Descrip- tive Evidence}

Figures 1 and 2 present the distribution by gender of literacy skills for 15-year old young students surveyed in 2003 by the PISA assessment for Germany and Italy. ${ }^{6}$ Both countries are characterized by a Secondary School system organized in separate tracks, which in principle should sort students according to their academic or vocational orientation. As long as literacy and some basic mathematical skills can be taken as proxies for individual cognitive abilities that favours the acquisition of additional schooling (comprising both innate ability and/or family influence in the early stage of child's development) ${ }^{7}$, these distributions suggest that sorting is far from perfect. However there are different degrees of "imperfection": in Germany the sorting seems to be more effective,

\footnotetext{
${ }^{6}$ The Pisa (Programme for International Student Assessment) is a survey coordinated by OECD and conducted by Canada Statistics (www.pisa.org). The first wave has been run in 2000 in 35 countries, while a second wave was run in 2003 in 48 countries. The aim of the programme is the assessment of student skills (literacy, mathematical, scientific knowledge and problem solving) in a comparable way across countries.

${ }^{7}$ Cunha et al. 2005 claim that human capital investment exhibits both self-productivity (skill attainment at one stage of the life cycle raises skill attainment at later stages of the life cycle) and complementarity (early investment facilitates the productivity of later investment).
} 
even if there still is a large overlapping in the tails of the distributions, suggesting that a significant share of students sorted in one type of schools would have been indistinguishable from students in another type. In order to provide a quantitative assessment of the extent of overlapping, in Table 1 we have computed the fraction of population belonging to the overlapping tails.

The comparison between the two countries indicates that the extent of overlapping is greater in Italy than in Germany: in Italy more than half on the students in the academic and vocational schools have a comparable level of ability as measured by these test scores, while this is true only for one forth of the students in the German sample. This is an indication that the tracking system as screening device based on ability works differently in the two countries. We believe that understanding the main features of this type of sorting has implications for the analysis of intergenerational mobility within each country. As long as sorting at secondary school level is mainly driven by family observable characteristics, intergenerational persistence is reinforced. On the contrary, whenever school allocation screens students on their innate abilities, being capable of matching students to their most appropriate destinations, opportunities for mobility are enhanced.

While Germany is considered the typical example of a separate track system, less information is available about Italy. Starting from its earliest stages, the educational system is organized as follows. Kindergarten starts at the age of 3 and ends at the age of 6 , and attendance is optional; it is organized and financed either by the central government or by local councils, and as a consequence school quality can be very different. Compulsory education ranges from 6 to 15 year old, and includes primary school (from 6 to 11, called scuola primaria), junior high (from 11 to 14, called scuola secondaria del primo ciclo) and the initial year of upper secondary school (which lasts from 14 to 17 or 19, depending on the chosen track). ${ }^{8}$ The upper secondary school (called scuola secondaria del secondo ciclo) is currently under reform. ${ }^{9}$ Despite the existence of different tracks, the upper secondary school could be described (and in the empirical analysis we follow this classification) as tripartite, with a an academic oriented generalist education provided by high schools ( 5 years, called licei, with further distinctions in humanities, scientific activities, languages, pedagogical sciences), a technical oriented education provided by technical schools (5 years, called istituti tecnici, with further differentiations) and a vocational train-

\footnotetext{
${ }^{8}$ Only starting from 1999 (law n. 9 20/01/1999), years of compulsory education have been raised from 8 to 9 , thus including 5 years of primary school, 3 years of junior high school and the initial year of upper secondary school (obviously conditional on not being failed at any point in the schooling career). The fiscal law for 2007 has raised the figure to 10 years, but it is not yet known how it will be implemented. Anyhow transition rates at the end of compulsory school age are currently above $90 \%$.

${ }^{9}$ To be more precise, the system has undergone a wave of reforms and counter-reforms in recent years: it was reformed in 2000 by the centre-left government, moving the compulsory requirement at age 16 and unifying the initial two years (Legge quadro n.30 of 10/2/2000). This has been modified in 2002 by the right-wing government in the opposite direction, lowering compulsory age to 15 and promoting the emergence of only two tracks, high schools (including former technical schools) and vocational schools (called alternanza scuola-lavoro Legge quadro n.53 of $28 / 3 / 2003)$.
} 
ing offered by local schools organized at regional levels (3 years, called istituti di formazione professionale). Until 1969, Italy was very similar to Germany with only one track granting College admission, another track granting admission only in a limited number of fields and the remaining tracks preparing for specific jobs (such as primary school teacher or construction site supervisor). The current system is still characterized by many tracks (38), but now all of them grant eligibility to College admission, conditioning on completing five years of secondary schooling (even students from vocational schools could enrol if they attend two integrative years). However, each of these tracks still predicts very different outcomes in terms of additional schooling acquired and labour market performance. More than $88 \%$ of students who graduate from Licei enrol in a University as opposed to $17.8 \%$ of the students coming from the vocational track. The choice on the type of secondary school to be attended is typically taken at the age of 13, during the final year of junior high school. Students and their families receive counselling from teachers, in some cases supported by psychologists, using students scores achieved during the compulsory school as one the driving guidelines for orientation. Therefore we may consider the Italian system a de facto early decision tracked system: despite the removal of legal barriers to university admission, attendance of different tracks has different implications for future educational career.

Also Germany is traditionally organized around three main tracks, even if relatively recent changes, in particular at State level, have created additional tracks. In the traditional system only students that graduate from one of the three tracks, the Gymnasium, are directly eligible for University admission. The decision of which track to enter is taken at the age of ten. ${ }^{10}$ Compulsory schooling starts at age six with primary school (Grundschule). It generally consists of 4 years of schooling in mixed-ability classes after which children are divided into the three main secondary school tracks, (Hauptschule, Realschule and Gymnasium). The Gymnasium or high school is the preferred school track taken by the most academically-inclined children and prepares pupils with 8 or 9 years of education ending with the Abitur, which is the required degree to enrol in university The Realschule or intermediate school is attended by children with medium levels of assessed ability at primary school and lasts 6 years (5th to 10th grade). Pupils with only low average academic achievement at the primary school generally enrol in the Hauptschule, consisting of 5-6 years of schooling. ${ }^{11}$ In more recent years there have been several attempts to introduce comprehensive schools (as for example in Berlin area), but overall the system remains separate. In Germany local educational authorities have more power in orienting students' choice: in some Länder parents are not entitled to choose

\footnotetext{
${ }^{10}$ We draw on Schnepf 2000 and Dustmann 2004 for a description of the German educational system. One ha to bear in mind that the German educational system is not fully homogenous, since the organization is state (Länder) specific. We report what is indicated as the "prevailing" pattern: see Eurydice 2002.

${ }^{11}$ In more recent years there have been several attempts to introduce comprehensive schools (as for example in Berlin area), but overall the system remains separate. To see how we have constructed our classification see the 7 .
} 
a track different than the one recommended, while in others they have to pass through consultation before changing the choice.

As a consequence, we expect that the role of parental background being more relevant in Italy than in Germany, given the greater freedom of choice they can exert in the secondary school choice. Looking at the evidence obtainable from the PISA survey conducted in 2003 on 15-year-old students enrolled in secondary school (see table A.2.a and A.2.b), the sorting provides apparently similar outcomes: a little more than one third of students is allocated to academic track ( $41 \%$ in Italy and $34 \%$ in Germany), one third to technical schools, that typically qualify for entrance in the labour market in white collar jobs $(34 \%$ in Italy and $36 \%$ in Germany) and the residual fraction is destined to vocational schools. While PISA data set does not contain direct information on past school performance, we obtain indirect evidence by observing whether a student has already been failed at least one year. The fraction of 15-year-old students who have been failed (probably due to scarce performance at previous stages) in Italy is $19.4 \%$ in vocational schools, $10.9 \%$ in technical schools and $4.5 \%$ in high schools, while comparable figures for Germany are $28.5 \%, 17.2 \%$ and $5.7 \%$. On other dimensions the two samples look rather similar: the average performance of students (that we take as proxy for unobservable abilities) in the two countries is comprised in a standard deviation interval, and therefore Italian and German students are indistinguishable in this respect. In terms of family background information, parental education is similar, even if the fraction of at least one graduate parent is lower in Italy, in accordance with aggregate evidence. ${ }^{12}$

In the sequel, we present a simple model where tracks choices can depend on either ability (when observable) or family background (when ability is not directly observable, and has to be inferred from parental education). Not surprisingly, we show that when ability is perfectly observable, mismatch between ability and school types is minimized, whereas (expected) total production is maximized.

\section{A simple model of school-track choice}

To clarify the role of ability and parental background on school choice, we develop a very simple non-overlapping generations model where the link across generations is due to endogenous schooling decision and exogenous intergenerational transmission of ability. We assume there is an inherent persistence in ability transmission between generations: this is the source of the fundamental identification problem we face in the empirical work since ability is also positively correlated with education.

We consider two polar cases, depending on information available to parents. In the first case, parents directly observe the realization of ability in their children before choosing their school and, given our assumption about skill formation, optimally select the type of school. Such behavior generates tracking

\footnotetext{
${ }^{12}$ The fraction of population aged 25-64 with a tertiary degree is $23 \%$ in Germany and $10 \%$ in Italy (OECD 2004, Education at a glance, table A1.1).
} 
by ability in the sense that students are allocated in the track that generates higher returns given their ability. In the second case, parents cannot observe talent realization in their offspring before making educational choices, and have to make inference from their own endowment of ability, which is freely observable once they have attended school. Therefore ex-post we will have a tracking by family background in the sense that the exogenous persistence of ability is endogenously magnified by the schooling choice leading to mismatches between ability and school track.

These two polar cases may constitute a metric to rank school systems since eventually any school system tracks students. For example, a school system that tracks individuals at a later age may get closer to a tracking by ability because individuals have more time to reveal their ability. However, an early tracking system that puts effort, through incentive and learning, in implementing tracking by ability may even be more successful because trough a more targeted education and peers effects may increase learning and detect mismatches earlier.

The model consists of three elements that describe the information set, the choice variables and the outcome variables. These three elements are the description of individual ability, the schooling/track decision and the labour market. The link between generations is the transmission of ability and information and the schooling choice.

We model ability and its intergenerational transmission following Checchi, Ichino and Rustichini 1999. Ability is defined as a realization from two types of ability:

$$
a \in\{H, L\}
$$

and its intergenerational transmission follows a first-order Markov process:

$$
\begin{array}{ll|c|c|} 
& \multicolumn{3}{c}{\text { Son }} \\
\multirow{2}{*}{\text { Father }} & \multicolumn{1}{c}{\mathrm{L}} & \mathrm{H} \\
\cline { 3 - 4 } & \mathrm{H} & \gamma & (1-\gamma) \\
\cline { 3 - 4 } & & (1-\gamma) & \gamma \\
\cline { 3 - 4 } & & &
\end{array}
$$

with $1 / 2<\gamma<1$. Persistency in abilities $(\gamma>1 / 2)$ is motivated by both nature (genetic) and nurture because in the empirical specification we will observe ability when children are about 15 years old and therefore already socialized.

Schooling is divided in two tracks:

$$
\tau \in\{A, V\}
$$

and the choice of a track is the only choice variable. Schooling is essentially a production function that transforms ability in skills. Skills will then have returns in the labor market.

Ability and track can be matched differently. The different probability of success in acquiring skills $\pi_{i j}$ determines which match $(a, \tau)$ is better, i.e. the ability type $H$ is a better match for the $A$ track because $\pi_{A H}>\pi_{A L}$ while the ability type $L$ is a better match for the $V$ track because $\pi_{V L}>\pi_{V H} \cdot{ }^{13}$

\footnotetext{
${ }^{13}$ Note that "probability of success" here does not simply mean to complete schooling but it means to actually acquire the skills.
} 
This is a very simple way to capture some multi-dimensionality in the notion of ability: there is not a single ability that allows individual to perform better in any field but some abilities are better in certain field ( $H$ is better in the $A$ track) while others are better in other fields ( $L$ is better in the $V$ track). The track $A$ guarantees an higher 'quantity' of skill $\left(s_{A}>s_{V}\right)$ - that may be interpreted as well as more years of schooling - but at an higher cost $k>0$. There are rational expectations, therefore the realized proportion of success in the population are equal to the expected probabilities. When unsuccessful, no skill is acquired. From this setting we get the following expectation over skill acquisition:

$$
\begin{aligned}
E(\operatorname{skill} \mid A, a) & =s_{A} \pi_{A a}-k \\
E(\operatorname{skill} \mid V, a) & =s_{V} \pi_{V a}
\end{aligned}
$$

The labour market is very simple and describes a standard human capital model where skills (or years of schooling) have a positive return determining the following wages:

$$
w=r s_{A, V}
$$

Note that if no skills are acquired (which occurs with probability $\left(1-\pi_{\tau a}\right)$ ), the wage is (normalized to) zero.

\subsection{Case 1: Tracking by Ability}

If ability is perfectly observed when choosing $\tau$ the decision problem is:

$$
\text { Choose } \tau \in\{A, V\} \text { to maximize } E(w \mid a)
$$

The optimal decision rule can be described as follows. If the child has ability $a=H$, then it will be optimal to choose the academic track, $\tau=A$, if and only if:

$$
\begin{aligned}
E(w \mid A, H) & >E(w \mid V, H) \\
r s_{A} \pi_{A H}-r k & >r s_{V} \pi_{V H}
\end{aligned}
$$

Therefore all parents with child's endowment $a=H$ will choose the $A$ track if the cost differential is low enough:

$$
k<s_{A} \pi_{A H}-s_{V} \pi_{V H} \equiv k_{1}^{*}
$$

If the child is has ability $a=L$, then it will be optimal to choose the vocational track, $\tau=V$ when:

$$
\begin{aligned}
E(w \mid V, L) & >E(w \mid A, L) \\
r s_{V} \pi_{V L} & >r s_{A} \pi_{A L}-r k
\end{aligned}
$$

therefore all parents with child's endowment $a=L$ will choose the $V$ track if the cost differential is high enough:

$$
k>s_{A} \pi_{A L}-s_{V} \pi_{V L} \equiv k_{1}^{* *}
$$

Note that by definition of the match ability/track we obtain the following. 
Lemma 1 The set of cost such that a separating equilibrium is realized is not empty

$$
k_{1}^{*}>k_{1}^{* *}
$$

Proof. By definition:

$$
\begin{aligned}
k_{1}^{*}-k_{1}^{* *} & =s_{A} \pi_{A H}-s_{V} \pi_{V H}-\left(s_{A} \pi_{A L}-s_{V} \pi_{V L}\right) \\
& =s_{A}\left(\pi_{A H}-\pi_{A L}\right)+s_{V}\left(\pi_{V L}-\pi_{V H}\right)>0
\end{aligned}
$$

since $\pi_{A H}>\pi_{A L}$ and $\pi_{V L}>\pi_{V H}$.

Therefore we obtain one region of attendance costs that determines a separating equilibrium and two regions that determine a pooling equilibrium. The following definition summarizes these results.

\section{Definition 2 Equilibrium:}

- if $k_{1}^{* *}<k<k_{1}^{*}$ a separating equilibrium where all $a=H$ choose track $A$ and all $a=L$ choose track $V$ is realized. Total (net) expected production in each period $t$ is equal to:

$$
W_{t}(1)=r s_{V} \pi_{V L} L_{t}+\left(r s_{A} \pi_{A H}-r k\right) H_{t}
$$

- if $k<k_{1}^{* *}$ a pooling equilibrium where all $a \in\{H, L\}$ choose track $A$ is realized. Total (net) expected production in each period $t$ is equal to:

$$
W_{t}(1)=r s_{A}\left(\pi_{A L} L_{t}+\pi_{A H} H_{t}\right)-r k\left(L_{t}+H_{t}\right)
$$

- if $k_{1}^{*}<k$ a pooling equilibrium where all $a \in\{H, L\}$ choose track $V$ is realized. Total (net) expected production in each period $t$ is equal to:

$$
W_{t}(1)=r s_{V}\left(\pi_{V L} L_{t}+\pi_{V H} H_{t}\right)
$$

Of course, none of these equilibria is inefficient in the sense that, conditioning on the exogenous cost of schooling, no Pareto improvement is present. Moreover, for sufficiently low or sufficiently high costs tracks basically disappear. However, in a situation of intermediate costs, tracks are a way to realize efficient sorting in the sense that different types of ability are revealed by not requiring the acquisition of the same amount of schooling. We look at this intermediate range of costs as the most likely to approximate the empirical data. In such a context an "efficient match" is a match of $\mathrm{H}$ ability individuals to the A track and $\mathrm{L}$ ability individuals to the $\mathrm{V}$ track. This is exactly the equilibrium realized under perfect information.

Total production in steady state is easily obtained because the ergodic distribution is $H=L=0.5$ of the measure one of individuals. In this respect an interesting remark is that there is not an optimal $\gamma$ in the separating equilibrium case. This is shown by noticing that in steady state distribution an equal proportion of both types is generated, so total net production is: 


$$
\begin{aligned}
W_{S S}(1 \mid k) & =\frac{r}{2}\left[\left(s_{A} \pi_{A H}-k\right)+s_{V} \pi_{V L}\right] \\
\text { with } k_{1}^{*} & >k>k_{1}^{* *}
\end{aligned}
$$

which is independent from $\gamma$ : under perfect information $\gamma$ plays a role only in the transition of abilities. Since however the type of school is optimally selected for all individuals, the possibility of failure in acquiring skill is independent of the degree of intergenerational persistence.

\subsection{Case 2: Tracking by Family Background}

Now assume that ability is not perfectly observed when choosing $\tau$ but that the information set includes wages and $\tau$ choices of the previous generation together with full information of the Markov process. From this information set the parent predicts the type of her own child and her expected wages. The problem will then be:

$$
\text { Choose } \tau \in\{A, V\} \text { to maximize } E\left(w \mid a_{t-1}\right)
$$

Suppose we start from a separating equilibrium: if this is the case, knowing the school choice of the previous generation means knowing parent's ability with probability one. Therefore the optimal decision rule will be

If $a_{t-1}=H$, choose $\tau=A$ when:

$$
\begin{aligned}
E_{t}\left(w \mid A, a_{t-1}=H\right) & >E_{t}\left(w \mid V, a_{t-1}=H\right) \\
\gamma\left(r s_{A} \pi_{A H}-r k\right)+(1-\gamma)\left(r s_{A} \pi_{A L}-r k\right) & >\gamma r s_{V} \pi_{V H}+(1-\gamma) r s_{V} \pi_{V L}
\end{aligned}
$$

therefore all the parent $H$ will choose the $A$ track for their children if the cost differential is low enough:

$$
\begin{aligned}
k<s_{A}\left[\gamma \pi_{A H}+(1-\gamma) \pi_{A L}\right]-s_{V}\left[\gamma \pi_{V H}+(1-\gamma) \pi_{V L}\right] \equiv k_{2}^{*} \\
\text { If } a_{t-1}=L, \text { choose } \tau=V \text { when: } \\
E_{t}\left(w \mid V, a_{t-1}=L\right)>E_{t}\left(w \mid A, a_{t-1}=L\right) \\
\gamma r s_{V} \pi_{V L}+(1-\gamma) r s_{V} \pi_{V H}>\gamma\left[r s_{A} \pi_{A L}-r k\right]+(1-\gamma)\left[r s_{A} \pi_{A H}-r k\right]
\end{aligned}
$$

therefore all the parents $L$ will choose the $V$ track for their children if the cost differential is high enough:

$$
k>s_{A}\left[\gamma \pi_{A L}+(1-\gamma) \pi_{A H}\right]-s_{V}\left[\gamma \pi_{V L}+(1-\gamma) \pi_{V H}\right] \equiv k_{2}^{* *}
$$

Again, from the definition of the match ability/track we can obtain the following.

Lemma 3 The set of cost such that a separating equilibrium is realized is not empty

$$
k_{2}^{*}>k_{2}^{* *}
$$


Proof. Again the statement is proved by the ratios of the probabilities of success and by persistency in intergenerational transmission of ability $(1 / 2<\gamma<1)$.

$$
\begin{aligned}
k_{2}^{*}> & k_{2}^{* *} \\
& s_{A}\left[\gamma \pi_{A H}+(1-\gamma) \pi_{A L}-\gamma \pi_{A L}-(1-\gamma) \pi_{A H}\right] \\
> & s_{V}\left[\gamma \pi_{H V}+(1-\gamma) \pi_{L V}-\gamma \pi_{L V}-(1-\gamma) \pi_{H V}\right] \\
L H S= & s_{A}(2 \gamma-1)\left[\pi_{A H}-\pi_{A L}\right]>0 \\
R H S= & s_{V}(2 \gamma-1)\left[\pi_{V H}-\pi_{V L}\right]<0
\end{aligned}
$$

Therefore we obtain the same structure of equilibrium defined in the first case: for low costs all types choose the $A$ track, for high costs all types choose the $V$ track and for intermediate costs they sort between the two tracks but less efficiently than in the first case because ability is not known at the moment of the choice. The following definition summarizes these results.

\section{Definition 4 Equilibrium:}

- if $k_{2}^{* *}<k<k_{2}^{*}$ a separating equilibrium where all $a_{t-1}=H$ choose track $A$ and all $a_{t-1}=L$ choose track $V$ is realized. Total (net) expected production in each period $t$ is equal to:

$$
W_{t}(2)=r s_{V} \pi_{V L}\left[\gamma L_{t}+(1-\gamma) H_{t}\right]+\left(r s_{A} \pi_{A H}-r k\right)\left[(1-\gamma) L_{t}+\gamma H_{t}\right]
$$

- if $k<k_{2}^{* *}$ a pooling equilibrium where all $a_{t-1} \in\{H, L\}$ choose track $A$ is realized. Total (net) expected production in each period $t$ is equal to:

$$
W_{t}(2)=r s_{A}\left(\pi_{A L} L_{t}+\pi_{A H} H_{t}\right)-r k\left(L_{t}+H_{t}\right)
$$

- if $k_{2}^{*}<k$ a pooling equilibrium where all $a_{t-1} \in\{H, L\}$ choose track $V$ is realized. Total (net) expected production in each period $t$ is equal to:

$$
W_{t}(2)=r s_{V}\left(\pi_{V L} L_{t}+\pi_{V H} H_{t}\right)
$$

As a first step to compare this equilibrium with the previous equilibrium, it is interesting to ask whether the set of costs generating a separating equilibrium under imperfect information is larger or smaller than the set of costs under perfect information. As expected, the set of costs under imperfect information is smaller as proved in the following.

Lemma 5 The set of cost such that a separating equilibrium is realized is smaller under imperfect information than under perfect information:

$$
k_{1}^{* *}<k_{2}^{* *}<k_{2}^{*}<k_{1}^{*}
$$


Proof. The higher upper-bound in the first case is due to:

$$
\begin{aligned}
k_{1}^{*} & >k_{2}^{*} \\
s_{A} \pi_{A H}-s_{V} \pi_{V H} & >s_{A}\left[\gamma \pi_{A H}+(1-\gamma) \pi_{A L}\right]-s_{V}\left[\gamma \pi_{H V}+(1-\gamma) \pi_{L V}\right] \\
s_{A}(1-\gamma)\left[\pi_{A H}-\pi_{A L}\right] & >0>s_{V}(1-\gamma)\left[\pi_{V H}-\pi_{V L}\right]
\end{aligned}
$$

and the smaller lower-bound in the first case is due to:

$$
\begin{aligned}
k_{1}^{* *} & <k_{2}^{* *} \\
s_{A} \pi_{A L}-s_{V} \pi_{V L} & <s_{A}\left[\gamma \pi_{A L}+(1-\gamma) \pi_{A H}\right]-s_{V}\left[\gamma \pi_{V L}+(1-\gamma) \pi_{V H}\right] \\
s_{V}(1-\gamma)\left[\pi_{V H}-\pi_{V L}\right] & <0<s_{A}(1-\gamma)\left[\pi_{A H}-\pi_{A L}\right]
\end{aligned}
$$

We can now rank the equilibria under ability sorting and under family background sorting by looking at total net production and at the amount of mismatches in the two cases. The following table shows the total net production differentials:

\begin{tabular}{lc}
\hline Cost & Differential: \\
& $W_{t}(1)-W_{t}(2)$ \\
\hline$k>k_{1}^{*}$ & 0 \\
$k_{1}^{*}>k>k_{2}^{*}$ & $\left(k_{1}^{*}-k\right) H_{t}>0$ \\
$k_{2}^{*}>k>k_{2}^{* *}$ & $(1-\gamma)\left\{\begin{array}{c}{\left[r s_{V} \pi_{V L}-\left(r s_{A} \pi_{A H}-r k\right)\right] L_{t}} \\
+\left[\left(r s_{A} \pi_{A H}-r k\right)-r s_{V} \pi_{V L}\right] H_{t} \\
k_{2}^{* *}>k>k_{1}^{* *}\end{array}\right.$ \\
$k_{1}^{* *}>k$ & $\left(k-k_{1}^{* *}\right) L_{t}>0$ \\
0
\end{tabular}

If the cost is very high (first row), the $V$ track is too expensive for any type and every individuals will choose the $V$ track independently of information and ability type. If the cost is lower (second row) knowledge of your own ability allows more efficient choices, i.e. a separating equilibrium emerges under perfect information but it does not under imperfect information. That is why the differential is proportional to the proportion of $H$ ability type in the population and to the distance of the actual cost from the threshold cost $k_{1}^{*}$. If the cost is lowered further, we enter in an area where both ability sorting and family background sorting generate a separating equilibrium (third row). However, the sorting under family background is less efficient generating the following mismatch: a proportion $(1-\gamma)$ of $H$ ability individuals choose the $V$ track while the $A$ track would have been more productive for them and, conversely, a proportion $(1-\gamma)$ of $L$ ability individuals choose the $A$ track instead of the $V$ track. This mismatch generates a differential that is proportional to the cost of choosing the "wrong" track (the two terms in squared parentheses) weighted by the proportion of the ability type making the mistake ( $L$-type in the first case and $H$-type in the second case). Since under incomplete information parents infer the child's type from their own type, the differential is also proportional to the parameter of intergenerational persistency in ability $(\gamma)$. If the cost is lower 
(fourth row) the gain in sorting by ability is again given by mismatch: under sorting by family background all individuals choose the $A$ track while for ability $L$ individuals the $V$ track would have been better. Finally, if cost are very low (last row), there is no mismatch and all individuals choose the $A$ track in both environments.

Another couple of remarks derived from the model are the following.

In the limiting case $\gamma=1 / 2$ individuals cannot infer any information on their own type from their parent's type. As expected following from this intuition, there is no separating equilibrium and one of the two pooling equilibrium will emerge depending on costs. The threshold over $k$ separating the two pooling equilibria is:

$$
\bar{k}=\frac{1}{2} s_{A}\left(\pi_{A H}+\pi_{A L}\right)-\frac{1}{2} s_{V}\left(\pi_{H V}+\pi_{L V}\right)
$$

Therefore, for costs higher than $\bar{k}$ all individuals will choose the vocational track and for cost lower than $\bar{k}$ all individuals will choose the academic track.

The second remark concerns the steady state, since the two environments, sorting by ability and sorting by family backgrounds, do not converge in steady state. In the most interesting region, i.e. for costs generating a separating equilibrium in both cases, the differential will be:

$$
\begin{aligned}
& W_{S S}(1 \mid k)-W_{S S}(2 \mid k) \\
= & \frac{r}{2}\left\{s_{A}(1-\gamma)\left[\pi_{A H}-\pi_{A L}\right]+s_{V}(1-\gamma)\left[\pi_{V L}-\pi_{V H}\right]\right\}>0 \\
\text { with } k_{2}^{*}> & k>k_{2}^{* *}
\end{aligned}
$$

again due to the mismatch of individuals in wrong tracks in the incomplete information case.

In conclusion, our simple model shows that when sorting by ability is possible, efficient allocation is achieved and output is maximized. On the contrary, under imperfect information on ability, tracking is based on parental education (due to inference on parental abilities), there is misallocation (i.e. a positive proportion of individuals are making choices that ex-post are revealed wrong with respect to their true abilities ending up in a bad $(a, \tau)$ match) and output is reduced.

The empirical implications we draw from the model are as follows. In the previous section we have shown that data for Italy and Germany generate misallocation of individuals over tracks. Moreover, the amount of misallocation is higher in Italy than in Germany. We interpret this evidence as the result of Germany being closer than Italy to the notion of tracking on ability. As empirical implication from the present model, we should therefore find stronger impact of family background in Italy than in Germany. The following two sections are devoted to study this impact. We thus analyze the impact of some measures of family background and some proxies for ability onto three choice variables: the type of secondary school attended; the attitudes toward acquiring additional education after completing the secondary school level; and the actual choices made after completing the secondary school level. Our results suggest that despite its 
apparent greater flexibility (parents are free to choose the type of secondary, enrolment at university is independent of the type of secondary school attended) the Italian educational system is less effective in sorting students according to their ability when compared to the German one.

\section{Impact of Family Background on Secondary Schooling}

\subsection{Empirical Specification}

Estimation of the determinants of the choice of the Secondary School track requires at least three sets of variables. First, we need a dependent variable that includes not simply the usual information about the schooling level completed but also a disaggregation by type of schooling tracks. Second, we need a measure of family background and in particular of the cultural background. Third, on top of the usual demographic controls, we need a measure of the specific ability of the individual. The PISA data set is one of the few that allows for the constructions of these type of variables in a comparable way across countries. ${ }^{14}$

In terms of the dependent variable, PISA data include the secondary school track for each student, usually aggregated in about five or six categories. As discussed in Section 2, we impose an additional aggregation to make Germany and Italy more comparable. In the final specification we consider three tracks based on the following definition: the Academic track groups tracks that typically lead to the acquisition of additional schooling at the tertiary level; the Technical track includes tracks that leave the option to acquire additional schooling but under some additional constraints; finally the Vocational track includes tracks teaching specific skills designed to enter the labor market right after completion. The mapping from the raw tracks available in PISA and our three-tracks specification is provided in Appendix 7 along with a more detailed discussion about the criteria we used to group them.

To describe family background we would ideally like having information about earnings, wealth and schooling of the family the student is living and has lived with. PISA data provide very detailed information on some psychological and social aspects of the family the student is living with but it does not provide income variables. ${ }^{15}$ However our focus is on parent's education, provided by a sufficiently disaggregated grade completed variable, and we control for other family background by using an Index of Socioeconomic Status, computed by

\footnotetext{
${ }^{14}$ For Italy, this is probably the only dataset on which something like this is possible. Previous works, as for example Flabbi 2001, have used the typical source of household data for Italy, the Bank of Italy Survey on Household Income and Wealth, but this data set does not include information on the type of secondary school track completed, while only limited information on family background (and no information on ability) is available. Therefore authors were forced to use only young individuals living with their parents as estimation sample.

${ }^{15} \mathrm{~A}$ word of caution is required about this type of information in PISA since the information is provided by the 15-year-old themselves.
} 
PISA analysts based on parental occupations, and by constructing other potentially relevant variables (such as the number of books in the house). ${ }^{16}$

Measures of individual ability are essential to reduce individual heterogeneity when estimating the impact of parents' schooling on the secondary school track chosen for their children. In PISA survey four different types of cognitive tests are performed, and special care is put to make them comparable across countries and across tracks. The four types of tests are aimed to measure: (i) mathematical ability; (ii) reading and writing skills; (iii) knowledge of science and (iv) problem solving. ${ }^{17}$ Moreover, PISA data control for past school experience (failure in any previous grade) and for faster than usual completion of grades.

The empirical specification we will assume is a standard Random Utility Model (RUM) specified as a Multinomial Logit (MNL) model, the most popular specification when studying discrete choice models with more than two alternatives. In our case we have three possible choices, denoted by $k \in\{1,2,3\}$, that each individual, denoted by $i \epsilon\{1,2, \ldots N\}$, has to take based on the following expected utility:

$$
U_{k, i}=x_{i}^{\prime} \beta_{k}+\varepsilon_{k, i}
$$

where $x_{i}^{\prime} \beta_{k}$ denotes the deterministic component and $\varepsilon_{k, i}$ the random component. The optimal strategy is to choose the alternative with the higher expected utility, leading, for example, to the following probability to choose alternative $k=1$ :

$$
P(1 \mid\{1,2,3\})=P\left(U_{1, i}>U_{2, i}, U_{1, i}>U_{3, i}\right)
$$

Under the assumption that $\left(\varepsilon_{1}, \varepsilon_{2}, \varepsilon_{3}\right)$ are independently and identically distributed following a standard Extreme value (or Gumbel) distribution, McFadden 1973 shows that this probability reduces to:

$$
P_{i}(1 \mid\{1,2,3\})=\frac{e^{x_{i}^{\prime} \beta_{1}}}{\sum_{k=1}^{3} e^{x_{i}^{\prime} \beta_{k}}}
$$

that is the usual logistic form.

This brief review of the model is useful to emphasize three points. First, identification requires one of the expected utilities to be normalized to zero. This is an immediate consequence of the parametrization (1) and (3): the scale of the utility cannot be identified. Second, it is more interesting to look at the inference on the probabilities than on the expected utilities. Therefore we will focus on the estimated marginal effects and not on the estimated utility parameters $\widehat{\beta}_{k}$. We will call marginal effect also the discrete change in probability due to the impact of a dummy variable. Finally, the model and the parametric assumption on the errors lead to the property of Independence from Irrelevant Alternatives (IIA)

\footnotetext{
${ }^{16}$ We will use the complete set of these variables in one of the two specifications we will propose, labelled Richer Specification. The complete specification is in Appendix 7.

${ }^{17}$ Since each student receive only a fraction of the entire test for each area, the survey assignes five plausible values for each type of ability. Following a common practice, we have taken the average over the five.
} 
in the choice. From this property it is possible to obtain a specification test for the model, developed by Hausman and McFadden 1984. The intuition is simple: consider the ratio over the probabilities to choose two alternatives. If the IIA property holds, then estimating the model including or excluding "irrelevant alternatives", i.e. in this case the third remaining alternative, should not have much of an impact on the estimates for the two alternatives on which we were computing the ratio. The statistic is build as in a standard Hausman test where the unrestricted model includes the "irrelevant alternative" and the restricted model excludes it. ${ }^{18}$

The marginal effect we focus on is the change in probability due to a father or a mother holding a tertiary level degree (typically College). After estimating by maximum likelihood the MNL model previously described, we therefore compute the change in probability for each individual by:

$$
\Delta \widehat{P}_{i}\left(k \mid\{1,2,3\}, x_{i}\right)=\widehat{P}_{i}\left(k \mid\{1,2,3\}, d_{i}=1, x_{i}\right)-\widehat{P}_{i}\left(k \mid\{1,2,3\}, d_{i}=0, x_{i}\right)
$$

where the statement $\left(d_{i}=1, x_{i}\right)$ means that the dummy for having a mother or/and a father with College is set to one and all the other regressors are set to the original values for individual $i$. Since these marginal effects are unique for each individual and they are not linear in the observables we incur in the usual problem of how to give a sense of the average impact in the sample. We have chosen to provide four descriptive measures in the Tables reporting the results (Tables 2a and 2b): (i) the sample mean; (ii) the sample standard deviation over $\Delta \widehat{P}_{i}(k \mid\{1,2,3\})$; (iii) the marginal effect at the average sample values of the regressors and (iv) the proportion of individuals $i$ for whom the marginal effect is positive. Notice the difference between the sample mean of the marginal effect:

$$
\frac{1}{N} \sum_{i=1}^{N} \Delta \widehat{P}_{i}\left(k \mid\{1,2,3\}, x_{i}\right)
$$

and the marginal effect at the sample mean of the regressors:

$$
\Delta \widehat{P}\left(k \mid\{1,2,3\}, \frac{1}{N} \sum_{i=1}^{N} x_{i}\right)
$$

The first measure is a good descriptive statistic of the average marginal effect in the sample but it does not provide a clear way to assess the precision of the estimates because a measure of variation of this estimate will include both variation from the estimated values $\widehat{\beta}$ and variation from the sample. The second measure does not have an equally clear interpretation in terms of inference because an individual with all the regressors set at the sample mean is often not the "average individual" one has in mind when looking for descriptive statistics. On the other side, standard errors on (6) are informative and are obtained by bootstrapping.

\footnotetext{
${ }^{18}$ McFadden 1987 shows how to perform the test using a Lagrange Multipliers test strategy.
} 
In addition to these four descriptive statistics for the marginal effects we also provide the kernel density estimation of the distribution of the marginal effect in the sample (Figure 3) and some "counterfactual" marginal effects (Figure 4 and 5). These counterfactual marginal effects are obtained by setting all the values of the regressors at the sample mean except for the regressor reported in the $\mathrm{x}$-axis (and of course the regressor on which we are computing the marginal effect). Using the previous notation, the "counterfactual" marginal effect is defined as:

$$
\begin{gathered}
\Delta \widehat{P}_{i}\left(k \mid\{1,2,3\}, x_{i}\right)= \\
\widehat{P}_{i}\left(k \mid\{1,2,3\}, d_{i}=1, x_{j i}, \bar{x}_{-j}\right)-\widehat{P}_{i}\left(k \mid\{1,2,3\}, d_{i}=0, x_{j i}, \bar{x}_{-j}\right)
\end{gathered}
$$

where $\bar{x}_{-j}$ denotes the sample mean for all the regressors except the regressor $j$. In Figure 4 and 5, the value (7) is reported on the y-axis while the value for $x_{j i}$ is reported on the x-axis. These marginal effects should give a better sense of how the marginal effects change in the sample as we change one regressor at the time keeping everything else constant.

\subsection{Results}

Results about the marginal effects of parent's schooling on the secondary school track chosen by their children are reported in Tables $2 \mathrm{a}$ and $2 \mathrm{~b}$. The first Table reports estimates on the male sample and the second on the female sample. We have chosen to split the sample by gender because heterogeneity of behavior between men and women seems particularly relevant in this context. ${ }^{19}$

The third row of Tables $2 \mathrm{a}$ and $2 \mathrm{~b}$ reports the average marginal effect in the sample, statistic (5), computed for each choice and the fifth row the marginal effect at the sample mean of the regressors, statistic (6), computed for each choice. Looking at Males in Italy, under the basic specification we estimate that parents' College more than double the average observed probability to choose the Academic track. By this we mean that the average marginal effect (about 0.36 considering the mean and about 0.41 considering the impact at the mean of the regressors) will increase the probability to choose the academic track by a value higher than the observed probability (reported in the first row and equal to about 0.279 ). As reported in the seventh row, parents' College has a positive effect on the probability to choose the academic track and a negative effect on choosing the Vocational track for every individual in the sample. For about $14.4 \%$ of the sample, parents' College has also a positive effect on choosing the Technical track. The variation of these marginal impacts in the sample is quite large, as described by the standard deviation reported in the fourth row, while the estimates are reasonably precise as shown by the standard errors reported in parenthesis on row six. Standard errors are robust to heteroskedasticity due to clusters at school levels.

\footnotetext{
${ }^{19}$ Motivation can be found in the discrimination literature (for example Altonjii and Blank 1999) or in previous works more similar to what we do such as Dustmann 2004.
} 
The previous results are obtained under a Basic Specification that simply includes age (in months) as demographic control, the performance in the mathematical cognitive test as ability control and dummies for two levels of education completed by parents ("High School" or "College or more", "less than High School" being the excluded case) as family background controls. Dummies on parents' schooling are built by taking the maximum schooling level completed by at least one parent; an additional dummy is included to take into account which of the two parents (either father or mother) has the highest education. This Basic Specification is mainly for comparison purposes while the Richer Specification includes all the useful variables we can obtain from the PISA data set without losing too many observations due to missing values. The complete specification is reported in Appendix together with complete results from MNL estimates (see tables A3.a and A.3.b). It adds a full array of controls for ability and family background leading to a smaller impact of parents' schooling on track choices. However, the impact is still substantial with an increase in the probability to choose the Academic track of about 50\% on average. Again the estimates are reasonably precise, except for the marginal effect on choosing the Vocational track.

Estimates on the male German sample shows a similar picture in terms of the direction of the impact but the magnitude is always smaller than in Italy. Parents' College still has a substantial and significant impact in increasing the probability to choose the academic track: the magnitude is about $50 \%$ on average under the basic specification and about $30 \%$ on average under the richer specification. We find this a very useful comparison to judge the magnitude of these impacts. Previous works have looked at Germany as a typical example of a country with relatively low intergenerational mobility and at its secondary school tracking system as an important factor in explaining this fact (Dustmann 2004, Schnepf 2002). We confirm this prediction but we also show that in another European country with a milder tracking system this effect is even more pronounced.

The average impact for women is relatively smaller in both countries: the increase in the probability to choose the academic track due to at least one parent with a Tertiary degree is about $70 \%$ and $35 \%$ on average in the two specifications for Italy and $62 \%$ and $32 \%$ on average in the two specifications for Germany. Differently from before there is almost no difference in the relative impact between Italy and Germany. This is due to the fact that parents' impact is more important for male children than for female children in Italy while in Germany the impact is almost equivalent on both subsamples. Therefore the policy implications are sort of gender neutral in Germany while in Italy the major problem seems the inefficient allocation of male students due to a huge impact of parents' education even when controlling for quite detailed measures of ability and for additional family background variables.

In terms of specification, the IIA test in general does not reject that this property, implied by the MNL model, is valid and therefore does not reject the specification we use. This is true for quite high $\mathrm{P}$-values for all the specifications 
estimated on both samples on both countries ${ }^{20}$. In terms of fit of the model, we just report in the second row the predicted probability at the mean of the sample: this very crude measure of fit shows a better fit on the Italian sample than on the German sample. In particular, we systematically under-predict the choice of the Academic track in Germany.

As already clear from the standard deviations reported in Table 2, there is a lot of variation in the marginal effect across the sample. It is therefore useful to have a sense of its distribution: Figure 3 reports the Kernel density estimation of the marginal effects on choosing the Academic track in the richer specification for each of the four sub-samples. As we can see the support is similar for all of them (from about zero to about 0.28 ) but the distributions are quite different. If for German females it is quite similar to a uniform, for Italian females we have a lot of probability mass around 0.2. Males are more similar across countries with a mode right above zero and another one above 0.2 . The picture we get from these distributions is slightly more complex than the one we obtain from simply looking at means. While when looking at means it seemed that women were more homogenous across countries, looking at the distribution this is not the case. A similar average effect is due in Italy to a lot of mass right below the 0.2 value while in Germany to a roughly constant distribution over the entire support. It becomes therefore interesting, in particular for Italy, to learn more about the individuals that experiment such a positive marginal effect. We investigate this by computing "counterfactual" marginal effects where we let vary one regressor at the time keeping the others at the sample mean.

The first interesting variable on which we perform the experiment is the index of socioeconomic status: are individuals that experiment the highest impact of parents' education coming from families with higher or lower economic status? In practice we are computing something similar to an interaction term but performed on counterfactuals. Figure 4 shows that in Germany the marginal effect is always increasing in the Parents Socioeconomic status: the higher the socioeconomic status the more important is the impact of the parents in increasing the probability to choose the academic track. This relation is roughly similar for men and women. For Italy we have a different picture: first, males and females are very different, second the relation is not monotone increasing. In particular, for females it is almost constant, decreasing only at very high levels of the socioeconomic status index, for males it is increasing and then decreasing. The decrease of the marginal effect for high level of socioeconomic status may seem counterintuitive (however it is still strongly positive), but can be rationalized when we consider that at very high levels the socioeconomic status becomes relatively more important than the education status in taking secondary school decisions.

The second group of variables we consider to build counterfactuals are scores on individual ability tests. The computation of marginal effects of parents education by ability is directly related with the considerations we sketched in our

\footnotetext{
${ }^{20}$ The only exception are females in Germany under the basic specification when we test excluding the Academic track. However, the test is not rejected when we used the richer specification.
} 
very stylized model. Since results are similar across the four types of ability indexes, we present in Figure 5 only results using the Combined Score in the Mathematical test. Even more than in the previous case, we see how much more different are the two countries when we look at the entire distribution of the marginal effects instead that at simple means of the marginal effects. For Germany the marginal impact of parents education in choosing the academic track is increasing in ability up to a score level well above the mean where it starts to decrease. For Italy, instead it is roughly constant with a mild decrease for high levels of ability. A potential interpretation of these results is as follows. In Germany, at very low levels of ability the probability to choose the academic track is very low and even the influence of parents education cannot overcome this fact. As ability increases, parents education becomes more and more a crucial factors. Finally for very high level of ability the probability to choose an academic track is so high that parents education loose importance. Of course, these are statements relative to Italy and not relative to a "fully efficient" outcome were ability should be the only predictor of track choices. In Italy, instead, the almost constant impact reiterates how persistent, and independent from ability, is the impact of parents education on track choices.

\section{Impact of Family Background on Post-Secondary Schooling}

Above the Secondary Schooling level the degree of comparability between Germany and Italy is radically reduced. First, in Italy any 5 -years Secondary School degree is sufficient to be admitted to College in any field of specialization. In Germany, instead, this is true only for the academic track whereas the technical track allows admission only to some post-secondary schools and the vocational track to none. Second, there is no dataset that collects the same information with the same criteria, as PISA does, on the two countries about Post-Secondary schooling. However, it is extremely interesting to have at least a glimpse at what happens right after secondary school. Are tracks a strong predictor of the total level of schooling completed? Have family backgrounds still a strong influence or is their influence limited to the secondary level?

To attempt to at least partially answer these questions we use two approaches. First, we further exploit the PISA survey by looking at student aspirations. In the questionnaire, surveyed students were asked about the level of educational attainment they expected to complete. Clearly, this is not the same as the actual choice but at least we can maintain some comparability across countries by using the same data source. Moreover, the determinants of aspirations are of some interest in themselves. Second, we use two different country-specific data sets to look at actual Post-secondary school choices. For Italy we use a Survey conducted by the Italian National Institute of Statistics (ISTAT) on a representative sample of individuals three years after graduation from Secondary School while for Germany we use a sample extracted from the 
German Socioeconomic Panel Study (SOEP). As we will explain in more details later, the extraction from the SOEP sample is obtained in way as to match the demographic characteristics of the Italian sample as much as possible.

\subsection{Determinants of Aspirations about Post-secondary School- ing}

The fraction of students expecting to enrol University is clearly different across tracks, but the differences in aspirations are also significant across countries: the $87.9 \%$ of students in the Italian academic track aspire to complete tertiary education (ISCED 5A-5B-6), while the same percentage declines to $51.3 \%$ among young Germans in the Gymnasium. The fraction of students aspiring to university enrolment is lower in technical schools $(39.2 \%$ in Italy and $24.0 \%$ in Germany) and quite small in vocational schools (24.7\% in Italy and $15.7 \%$ in Germany). ${ }^{21}$ The observation that the fraction of students planning to enrol university is larger in Italy than in Germany is consistent with what we have previously remarked about the screening abilities of these two educational systems. This is particularly true when we compare intention with actual behaviors: in 2002 (most recent data available) the $23.6 \%$ of the age cohort at the typical age of graduation attained a tertiary degree in Italy, while $29 \%$ of Germans in the same cohort achieved a degree. ${ }^{22}$

In table 3 we report the estimates for the coefficients of interest in a probit model predicting the aspiration to enrol university (full model estimates are reported in tables A.4.a and A.4.b in the appendix).

Two results are surprising: parental education is mostly significant only in Italy, even when fully accounting for ability (extended version), while it is almost insignificant in the German case. In addition, the probability impact of a graduate parent is higher in Italy, and more pronounced for males than for females. Measured ability does not seem to play any role, as if aspirations of students were independent of their school performance, conditioning on secondary school tracks. As expected, the type of secondary school attended affect the intention to enrol in University: if we compute the odd ratio of a student choosing the academic track compared with the technical track, it ranges between 6.0

\footnotetext{
${ }^{21}$ It is worth noticing that almost half $(45.3 \%)$ of the German students do not answer to this question, and the fraction is highest among students attending vocational schools (76.4\%). This is somewhat reasonable since they may intepret as the question not applying to them. Of course, it is still possible for a student in the vocational track to "aspire" to a College education because they can always integrate their vocational degree with additional education to get the appropriate degree to be admitted to College. If students in vocational schools tend to not express their aspirations, the fraction of students aspiring to university is likely to be overestimated in the German sample.

${ }^{22}$ Data from OECD 2004, Education at a glance, table A3.1. There are differences between countries at tertiary level that may be partially responsible for this difference: while Germany has a well developed technical tertiary education (ISCED 5B), Italy almost completely lacks this type of schools. The $29 \%$ of German students achieving a university degree is made of $9.8 \%$ from technical universities, $6.5 \%$ of students achieving a $3-4$ year degree and $12.7 \%$ of students attaining a 5-6 year degree. The corresponding figure for Italy are $0.9 \%, 2.5 \%$ and $20.2 \%$.
} 
and 2.8 in Italy and 2.0 and 0 in Germany. The analysis of students aspirations confirms what we have already found in the case of the secondary school choice: parental influence is higher in Italy than in Germany, even after controlling for the type of secondary school attended, which in turn plays a role in shaping expectations on the future. When looking at the full version of the estimated model, we notice that various abilities are more significant in Germany than in Italy, but this result suffer from multicollinearity among these variables; in addition, estimated signs are sometimes negative, thus contradicting theoretical expectations.

\subsection{Determinants of Post-secondary Schooling Choices}

By looking at the determinants of Post-Secondary school choices we want to see whether family influence on post-secondary schooling decision persist beyond the previous choice of a secondary school track. If this is not the case, we can claim that (one of) the main channel by which the family background affects long term schooling decision is the track choice at the secondary school level. Such a conclusion would constitute only a partial answer to our question if the secondary school system increases or decreases intergenerational mobility in schooling but it will be a clear indication of the direction that policy reforms should take to have a substantial impact. Otherwise, if we still find a persistent effect of parental education on post-secondary choices, even after controlling for secondary school attended, then we may question whether intergenerational mobility in incomes has most to do with educational choices, or rather with other factors (like social networking in the labor market, for example).

This strategy is a much more direct test than looking at aspirations but it comes at the cost of losing a data set that is very homogenous across countries, that is we do not have a data set with a structure similar to PISA to study post-secondary school decision. We are then looking at country-specific data sets that can have the information we need.

For Italy we use a Survey conducted by the Italian National Institute of Statistics (ISTAT) on a representative sample of individuals three years after graduation from Secondary School. Individuals were interviewed in 2001. After losing about $5 \%$ of the sample due to missing values, the final estimation sample is quite large, with 20929 valid observations. Some descriptive statistics on this sample are reported in Appendix (see Table A.5). For Germany we use the German Socioeconomic Panel Study (SOEP) for the year 2001 and 2002. We try to create a sample that can match the characteristics of the Italian sample as much as possible. We end up selecting individuals that have obtained their secondary school degree from at least 2 years and from no more than 10 years and that are between 18 and 30 years old. We do not match exactly the demographic characteristics of the Italian sample for a problem of numerosity. Even with these much larger intervals on age and years from graduation we can extract only 374 individuals with no missing values on the relevant variables for males and 430 for females. The crucial variable reducing the numerosity are the grades obtained in school, that we use to proxy ability, which are present 
in SOEP only starting in 2001. Some descriptive statistics on this sample are reported in Appendix.

Given the different structure of the data we will compare two different specifications for Italy and Germany. In particular, on the Italian sample we will be able to address also the dropped out behavior and we will also propose sequential logit estimates to better approximate the choice structure. On the German sample, instead, we will simply look at College enrollment and we will perform only standard logit. On a positive side we are using a probably better measure of parent's educational background because we know the secondary school track of the parents.

On the Italian sample we will work with a discrete choice model equal to the one described in the previous section with the difference that now the alternative choices are: (i) Never enrol in College (ii) Drop-out from College, and (iii) Complete College (as proxied by the fact of being still enrolled full-time after three years). Given the extremely high drop-out rate among College students in Italy, it seems particularly interesting to allow the model to capture this behavior. The data are appropriate because they identify individuals that enrolled in College after completing High School and dropped out sometime in the following three years. People still enrolled full-time after three years seems a reasonable proxy for individuals that will actually complete College. These three alternatives, though, have a particular structure because the choices are very likely to be taken sequentially: first individuals decide if enrolling in College or not and later, conditional on this choice and the ensuing performance, if staying in College or Drop-out. We will therefore focus on estimating a Sequential Logit model and we will report estimates from a Multinomial Logit model as a comparison. The sequential logit generates the following parametrization of the probability to choose each alternative:

$$
\begin{aligned}
P_{i}(\text { Never Enroll }) & =\frac{1}{1+\exp \left(x_{i}^{\prime} \beta\right)} \\
P_{i}(\text { Dropped-out } \mid \text { Enroll }) & =\frac{1}{1+\exp \left(x_{i}^{\prime} \alpha\right)} \frac{\exp \left(x_{i}^{\prime} \beta\right)}{1+\exp \left(x_{i}^{\prime} \beta\right)} \\
P_{i}(\text { Enrolled } \mid \text { Enroll }) & =\frac{\exp \left(x_{i}^{\prime} \alpha\right)}{1+\exp \left(x_{i}^{\prime} \alpha\right)} \frac{\exp \left(x_{i}^{\prime} \beta\right)}{1+\exp \left(x_{i}^{\prime} \beta\right)}
\end{aligned}
$$

from which it is possible to identify $(\alpha, \beta)$ by observing the choices and the regressors. Estimation will be performed by maximum likelihood.

Table 4 reports marginal effects of at least a parent with College on the Italian sample by gender. As in the previous section we use a basic specification and a richer specification. The main difference between the two specifications is about the proxies for ability: in the basic specification we simply control for the grade obtained at the end of lower secondary school (Scuola Media) while in the richer specification we build a 16 outcomes variable combining for each individual grades at the end of lower secondary school and grades at the end of secondary school. ${ }^{23}$

${ }^{23}$ The different way of building the ability controls generates a different numerosity for the 
Again as in the previous section we reports the average marginal effects, the marginal effects at the mean of the regressors and the proportion of individuals with a positive impact. For example the third row report the average marginal effect of at least one parent with College computed as in (5) while the fifth row computed as in (6). The main objective of the exercise is to see how the impact of parent's education changes when we control for secondary school tracks: in the Table this means to compare the first three columns with the last three columns.

Looking at Tables $4 \mathrm{a}$ and $4 \mathrm{~b}$, the sign of the impact is as expected on the Enrolled alternative - a positive impact of parents' College - and on the Never Enrolled alternative - a negative impact - while results are mixed on the Dropout alternative. The magnitude of the impact is huge without controlling for track on the male sample: having at least a parent with College increase the probability to be continuously enrolled in College by more than $100 \%$ even in the richer specification. On the female sample the impact is relatively lower but still quite high.

When secondary school tracks completed are controlled for the impact is significantly reduced: for both man and women the magnitude of the impact is about $45 \%$ lower. This suggests that the secondary school track is an effective channel of the impact of family background on the final level of schooling completed. However, even in the richer specification and with controls for tracks we observe a persistent direct effect of parents' education on College choices. ${ }^{24}$

The estimates are generally precise except for the Drop-out choice. We tentatively interpret this as a composition effect due to the higher heterogeneity of individuals choosing this alternative. In terms of the comparison between the Conditional Logit model and the Multinomial Logit model we observe some differences in the point estimates but similar qualitative results. As expected, the IIA test systematically rejects the independence assumption imposed by the Multinomial Logit model when the alternatives Drop-out and Enrolled are eliminated.

Results can be summarized as follows for Italy: (i) secondary school track controls imply a large and significant reduction of the impact of parents' education on College choices; (ii) the impact of family background is significantly smaller for women in all the specifications; (iii) a significant impact of parents' education on staying in College remains even after controlling for secondary tracks. The inference we draw from these results is consistent with what we have found in the previous section: (i) the secondary school track choice is one of the major channel of the intergenerational persistence in schooling levels but not the only one; (ii) women behavior is more independent from family

richer and basic specification because the 'grade obtained at the end of Scuola Media' has more missing values than the variables on the grades at the end of secondary school. In the richer specification we have chosen to input some of the missing scuola media grades based on the other individual characteristics and therefore generating a sample with more observations than the sample in the basic specification.

${ }^{24}$ A significant direct effect of parents' education on College choices is also the main result of Flabbi 2001 using a different, and less rapresentative, data set for Italy. 
backgrounds than men behavior.

As mentioned, in Germany the mapping from secondary school tracks and post-secondary school choices is very different than in Italy. We aggregate the post-secondary choices in three possible alternatives: (i) if enrolled in University or completed a University degree (includes University degrees (Universitaet) and Technical college degree (Fachhochschule)); (ii) if enrolled or completed a Postsecondary vocational degree or Apprenticeship (includes apprenticeship (Lehre), Vocational schools (Berufsfachschule), Technical school (Fachschule) and other training and vocational schools); (iii) if never enrolled in any Post-secondary degree and never obtained additional schooling on top of secondary schooling. Not all secondary school tracks are enough to be admitted to all the alternatives. Therefore we only select individuals that have completed a secondary school track that admits at least one choice in the three aggregate alternatives we have constructed. Namely, this implies eliminating individuals that have only completed the Hauptschulabschluss. Moreover we are forced to use only SOEP data from 2001 and 2002 to have grade information and to impose age limit to match the Italian data, as mentioned before. Due to these data limitations and the resulting low numerosity we have chosen a particularly parsimonious specification: the only demographic controls are age and martial status; the only family background controls are the "highest" secondary school track completed by the parents; and the only ability controls are the grades in mathematics at the of secondary school. We have also available grades in German but results are not sensitive to including grades in German or mathematics. ${ }^{25}$ The family background information we are choosing - secondary school track of the parents where we rank higher the academic track, followed by the technical track and by the vocational track - is highly correlated with the usual family background information used - highest level of schooling completed - but it is probably more appropriate to study the impact of secondary school tracks on intergenerational mobility in schooling.

The marginal effect we focus our attention on is the impact of having at least one parent with an Academic secondary school degree (Abitur) on the three alternatives described above. As on the Italian sample, we want to assess how this impact changes when we control for the secondary school track completed by the individual. Table 5 reports the results with the usual statistic: mean and standard deviation of the marginal effects in the sample, marginal effect at the mean and IIA tests. The complete set of results on the estimated coefficients from which we have computed the marginal effects is in Appendix.

In all the specifications, we obtain the expected sign: at least a parent with an academic degree increases the probability to choose a University degree and decreases the probability to choose a Vocational degree. The impact on the choice to never enroll in any Post-secondary degree is more mixed: it is on average positive but in many specifications it is very small or not significant. Moreover, this group of individuals has a very low numerosity so we consider

\footnotetext{
${ }^{25} \mathrm{~A}$ more complete set of ability controls that includes or combines all grades available generates too many dummies to guarantee a credible esimation.
} 
the estimated impacts on this alternative not very robust. Focusing on the impact of choosing a post-secondary vocational school or a University degree, we see some patterns similar to Italy: the impact is significant but it is reduced when secondary school tracks controls are included in the specification. This reduction, however, is relatively lower than on the Italian sample. Moreover, the result is more robust on the female sample than on the male sample. On the male sample, the positive impact on choosing the academic degree as measured by the sample mean of the marginal effect is almost unchanged when we introduce track controls. We read this generally lower changes when we introduce track controls as consistent with the Italy/Germany comparison of the previous section: secondary school track choices are less affected by family background in Germany than in Italy and therefore the residual impact of family background on post-secondary school choices is less sensitive to secondary school track controls.

\section{Conclusions}

The aim of the present paper is to study the interaction between family background and educational choice in tracked educational systems. The availability of a sorting device represented by different types of secondary schools (acad-

emic, technical or vocational) does not necessarily represent a reinforcement of social immobility, this depending on how students are allocated to tracks. At one extreme, one may think at a perfectly meritocratic system, where track allocation is based on pure ability. In this set-up, intergenerational mobility is at the highest, with the only limitation given by the correlation between child ability and parental education (which is typically referred in the literature as "genetic" transmission of ability). At the other extreme, one may think of a perfectly ascriptive system, where track allocation mainly depends on parental background: in this case mobility is lower, because children educational choices replicate parental ones (this has obviously to be interpreted in probabilistic terms: a graduate student is very likely to have studied in an academic track, which is very likely to have been chosen by graduate parents).

We have studied two countries, Italy and Germany, where the educational systems are characterized by a secondary school divided in separate tracks. We have shown that parental education (having at least one parent with college degree) increases the probability of selecting (or being selected into) an academic track, and this effect is stronger in Italy than in Germany, especially for boys ( $41 \%$ vs $14 \%$ for males, $35 \%$ vs $33 \%$ for females). However when we look at the distribution of marginal effects, the two countries are very different also on the female sample: parental education and individual ability seem complements in increasing the probability of selecting an academic track in Germany, but they are rather independent one from the other in Italy.

Our interpretation of these results is that sorting of students across secondary school tracks is closer to a sorting by ability in Germany and closer to a sorting by family background in Italy. By using a rich set of alternative 
proxies for students' abilities (based on their level of competencies and their previous educational career) and parental background (not just education, but financial resources - correlated with occupation - and cultural resources - correlated with books availability), we show that the latter group of variables is more relevant in the case of Germany than in the case of Italy, while the reverse situation applies with respect to parental background. Thus the same institutional framework may produce alternative outcomes, irrespective of the degree of institutional rigidities (which we have shown being higher in Germany than in Italy). The situation is maintained and aggravated when we extend our analysis to post-secondary choices. One of the main virtue of tracked educational system advocated by its supporters is the diversion of less talented students away from the educational ladder. If the track selection is working as a sorting device, the role of the family should vanish as long as a child has been sorted in the "right" track. But if the track selection can be overrun by family influence (students in academic track from poor background are led to dropout, while student in vocational tracks from good background are pushed towards post-secondary education), then even this supposed virtue of the tracking system tends to disappear. Our empirical analysis shows that parental influence on post-secondary choices is greatly reduced when we control for secondary school track on the Italian sample. On the German sample we find a similar result but with a much smaller magnitude. Also on post-secondary choices we confirm gender asymmetries, with women behavior more independent from family background in Italy and more dependent on it in Germany.

Compared to previous literature (Dustmann 2004, Schnepf 2002) our results point in a different direction. Previous works have looked at Germany as a typical example of a country with relatively low intergenerational mobility and at its secondary school tracking system as an important factor in explaining this fact. We show that this is not necessarily related to the tracking of the secondary school system itself, ${ }^{26}$ but to the way in which students are sorted. By providing evidence of another European country, Italy, with a more flexible tracking system (later selection, possibility to refuse teachers' advice), we show that parental background may be even more pronounced, thus yielding lower intergenerational mobility in educational attainments.

Our main policy implication is that tracking can be efficiently designed in order to reduce mismatch and increase intergenerational mobility: it requires sorting rules based on ability and not on parental background. This is not an easy task anyhow, since it requires to collect information on students (cognitive and non-cognitive) abilities, which are not necessarily available at early age. If the information when the relevant decision is taken is not enough the risk of mismatch is too high and the elimination (or the postponement) of tracks at secondary level could be considered as an appropriate second best. An alternative or complementary policy to achieve a progressive tracking by ability could be increasing mobility across tracks based on grades or standardized tests.

\footnotetext{
${ }^{26}$ Which may also have positive implications: for example Brunello and Hariga 2007 show that tracked educational systems raise the competences of adults once in the labor force.
} 
The worse of possible worlds is retaining separate tracks while eliminating any "institutional" tracking-by-ability feature. The result of such a system would be the reinforcement of parental influence on educational choices, leading to lower intergenerational mobility and to inefficient lock-in effects. Italy seems closer to such a system than Germany, a country for which some authors have already suggested to integrate the different tracks on efficiency grounds (Dustmann 2004). 


\section{Appendix}

\subsection{PISA Data}

The Pisa (Programme for International Student Assessment) is a survey coordinated by the OECD and conducted by Canada Statistics (www.pisa.org). The first wave has been run in 2000 in 35 countries, while a second wave was run in 2003 in 48 countries. The aim of the programme is the assessment of student skills (literacy, mathematical, scientific knowledge and problem solving) in a comparable way across countries.

The estimation sample is extracted from the raw data using the usual criteria, that is we keep observations that have no missing values over all the variables we use in the specification. This procedure generates small differences between the estimation sample in the basic specification and the estimation sample in the richer specification. We have tried to estimate the basic specification on the richer specification sample and results were not significantly different. In general the amount of observations we loose due to missing values is not too large and, by simply comparing descriptive statistics, does not seem to select the sample in any particular way. For sake of concision, we have chosen to present descriptive statistics only for the richer specification sample. They are reported in Table A.2.

Dependent variable: secondary school tracks.

We have chosen to aggregate the original tracks provided in PISA in the three tracks Academic, Technical and Vocational to increase the comparability across countries. For Germany we start with the three tracks division that is still at the core of the German secondary school system ${ }^{27}$ : Haputschule (Vocational), Realschule (Technical) and Gymnasium (Academic). We then allocate to Vocational the Berufschule and those remaining tracks that do not give access to upper secondary (Koop. Gesamtschule). We allocate to Technical those remaining tracks that give potential access to upper secondary but that are not Gymnasium (Comprehensive with access to upper secondary). Finally, we allocate to Academic those remaining tracks defined as upper secondary even if they are not called Gymnasium (Comprehensive in upper secondary).

For Italy, we defined the Academic track to include the tracks: Liceo Classico, Scientifico and Linguistico. We defined the Technical track to include the Istituti Tecnici and finally we define the Vocational track to include the Scuole Professionali and the Scuole d'Arte.

Regressors: ability indicators.

In addition to gender and age (measured in months), we consider whether foreign born (foreign) and/or whether speaking at home a different language (dialect). With respect to family background, we consider the highest educational attainment in the couple of parents (histedaggr1 = ISCED 0-1-2; histedaggr2 = ISCED 3-4; histedaggr3 = ISCED 5-6) and whether the mother is the highest educational attainment in the couple (mhist). In addition we also include parental occupation (through the highest occupational prestige in the parental couple -

${ }^{27}$ In italics we report the original tracks provided in the PISA raw data. 
hisei), as proxy of family income, whether the mother was working (housewife) and the number of boos available at home (books1 = up to 25 books; books2 = from 25 to 200 books; books $3=$ more than 200). We also include information whether both parents are living in the family (intact)

With respect to ability, we consider the test scores (averaged over the 5 plausible values) in the four areas (combmath $=$ numeracy; combread $=$ literacy; combscie $=$ scientific knowledge; combprob $=$ problem solving). We also look at previous educational career including information whether one is in line with the age profile of his/her cohort (regular1 = students lagging behind at least one year; regular $3=$ students one or more year ahead) and/or whether $\mathrm{s} /$ he has experienced being retarded at least once in previous year).

While parental background variables do not exhibit significant differences between genders, when going to ability boys are more likely to have experienced failures. They have higher test scores in math and science, and lower ones in literacy. 


\section{References}

[1] Acemoglu, D., and S.Pischke. 2001. "Changes in the wage structure, family income and children's education" European Economic Review 45: 890-904.

[2] Altonji, J and R.Blank. 1999. "Race and gender in the labour market". in O.Ashenfelter and D.Card (eds). Handbook of labor economics. vol.3: 3144-3260.

[3] Bradley, E.L. 1985. "Overlapping coefficients", in Kotz, S. and N.L.Johnson (eds) Encyclopedia of Statistical Sciences 6: 546-47

[4] Brunello, G. and D.Checchi. 2007. "Does School Tracking Affect Equality of Opportunity? New International Evidence" forthcoming in Economic Policy, August

[5] Brunello, G. and K.Hariga. 2007. "Does secondary school tracking affect performance ? Evidence from IALS". IZA Discussion Paper n.2643

[6] Cameron, S.V. and J.J. Heckman. 1998. "Life Cycle Schooling and Dynamic Selection Bias", Journal of Political Economy, 106: 262-333.

[7] Cameron, S.V. and J.J. Heckman. 2001. "The Dynamic of Educational Attainment for Black, Hispanic, and White Males", Journal of Political Economy, 109: 455-499.

[8] Cameron, S.V. and C. Taber. 2004. "Estimation of Educational Borrowing Constraints Using Returns to Schooling", Journal of Political Economy, $112(1)$.

[9] Chevalier, A., K.Denny and D.McMahon. 2005. "A multicountry study of intergenerational education mobility". mimeo.

[10] Checchi, D. 2003. "The Italian educational system: family background and social stratification", ISAE Conference on Monitoring Italy.

[11] Checchi, D. 1997. "Education and intergenerational mobility in occupations", American Journal of Economics and Sociology, 56/3: 331-352

[12] Checchi, D., A.Ichino and A.Rustichini. 1999. "More equal but less mobile ? Intergenerational mobility and inequality in Italy and in the US". Journal of Public Economics, 74: 351-393.

[13] Corak, M. 2006. "Do Poor Children Become Poor Adults? Lessons from a Cross Country Comparison of Generational Earnings Mobility". IZA Discussion Paper n.1993

[14] Comi, S. 2004. Intergenerational mobility in Europe: evidence from ECHP. CESIfo conference on Schooling and Human Capital Formation in the Global Economy (Munich September 2004). 
[15] Cunha, F., J.Heckman, L.Lochner and D.Masterov. 2005. "Interpreting the evidence on life cycle skill formation". NBER wp.11131, May

[16] Dardanoni, V. 1993. "Measuring Social Mobility". Journal of Economic Theory: $372-394$

[17] Dustmann, C. 2004. "Parental background, secondary school track choice, and wages", Oxford Economic Papers, 56: 209-230, 2004.

[18] Esping-Andersen, G. 2004. Unequal opportunities and the mechanisms of social inheritance in M.Corak (ed). Generational Income Mobility in North America and Europe. Cambridge University Press

[19] Eurydice 2002. Key data on education in Europe 2002. European Commission.

[20] Flabbi, L. 2001 "La Scelta della Scuola Secondaria in Italia", Rivista di Politica Economica, 91(7/8), 85-114.

[21] Grawe, N. 2004. "Intergenerational Mobility for Whom? The Experience of High and Low Earnings Sons in International Perspective" in M.Corak (editor) Generational Income Mobility in North America and Europe. Cambridge: Cambridge University Press.

[22] Hanushek, E and L.Woessman. 2005. "Does educational tracking affect performance and inequality? Differences-in-differences evidence across countries." NBER wp.11124, February.

[23] Hausman, J. and D. McFadden. 1984. "A specification Test for the Multinomial Logit Model", Econometrica, 52, pp. 1219-1240.

[24] Haveman, R. and B. Wolfe. 1995. "The Determinants of Children's Attaiments: A Review of Methods and Findings", Journal of Economic Literature, 33(4), 1829-1878.

[25] Keane, M.P. and K.I. Wolpin. 2001. "The Effect of Parental Transfers and Borrowing Constraints on Educational Attainment", International Economic Review, 42(4), November 2001.

[26] McFadden, D. 1987. "Regression Based Specification tests for the Multinomial Logit Model", Journal of Econometrics, 34, pp. 63-82.

[27] McFadden, D. 1973. "Conditional Logit Analysis of Qualitative Choice Behavior", in: P. Zarembka (ed.) Frontiers in Econometrics, New York: Academic Press.

[28] Mulligan, C. 1999. Galton versus the human capital approach to inheritance. Journal of Political Economy 107(6): S184-S224. 
[29] Schnepf, S.V. 2002. "A Sorting Hat that Fails? The Transition from Primary to Secondary School in Germany", Innocenti Working Paper No. 92, Florence: UNICEF Innocenti Research Center.

[30] Shea, J. 2000. Does Parents' Money Matter?. Journal of Public Economics. $77(2): 155-84$. 
Table 1 - Overlapping of ability distributions

\begin{tabular}{ccccc}
\hline & Italy males & Italy females & Germany males & Germany females \\
\hline Mathematical ability & & & & 0.62 \\
Vocational - Technical & 0.59 & 0.75 & 0.21 & 0.66 \\
Vocational - Academic & 0.39 & 0.62 & 0.47 & 0.26 \\
Technical - Academic & 0.74 & 0.84 & & 0.50 \\
Reading ability & & & 0.59 & 0.64 \\
Vocational - Technical & 0.62 & 0.75 & 0.22 & 0.26 \\
Vocational - Academic & 0.37 & 0.58 & 0.49 & 0.49 \\
Technical - Academic & 0.69 & 0.79 & & \\
\hline \hline
\end{tabular}

Note: the figures reported in the table correspond to the overlapping coefficient broposed by Bradley (1985): given two random variables, $x_{1}$ and $x_{2}$, and denoting with $f\left(x_{i}\right)$ their density functions (that we estimate through a kernel estimator - see figures 1 and 2), the overlapping coefficient is given by $O V L=\sum_{\times} \min \left[f\left(x_{1}\right) \cdot f\left(x_{2}\right)\right]$. The $O V L$ coefficient ranges between 0 and 1: a value of 0 implies absence of overlap (disjoint distributions), whereas a value of 1 indicates identical distributions. 
Table 2a: Marginal Effect of at least one Parent with College on Secondary School Track Choice. MNL Model - Males

\begin{tabular}{|c|c|c|c|c|c|c|}
\hline & \multicolumn{3}{|c|}{ Italy } & \multicolumn{3}{|c|}{ Germany } \\
\hline & Vocational & Technical & Academic & Vocational & Technical & Academic \\
\hline \multicolumn{7}{|l|}{ Basic Specification: } \\
\hline Observed Distribution & 0.273 & 0.448 & 0.279 & 0.357 & 0.349 & 0.293 \\
\hline Predicted Distribution & 0.241 & 0.526 & 0.233 & 0.374 & 0.497 & 0.129 \\
\hline \multicolumn{7}{|l|}{ Marginal effects: } \\
\hline Mean & -0.1307 & -0.2252 & 0.3559 & 0.0016 & -0.1475 & 0.1459 \\
\hline Standard Deviation & 0.0576 & 0.1607 & 0.1214 & 0.0362 & 0.0800 & 0.1141 \\
\hline \multirow[t]{2}{*}{ At $\bar{x}$} & -0.1880 & -0.2258 & 0.4138 & -0.0061 & -0.1427 & 0.1488 \\
\hline & $(0.0325)$ & $(0.0428)$ & $(0.0416)$ & $(0.0517)$ & $(0.0509)$ & $(0.0411)$ \\
\hline Proportion Positive & 0.0000 & 0.1440 & 1.0000 & 0.4683 & 0.0000 & 1.0000 \\
\hline IIA Test: P-value & 0.6616 & 0.6960 & 0.4451 & 0.9752 & 0.7203 & 0.7970 \\
\hline Log-likelihood & & -4761.3401 & & & -1545.99 & \\
\hline $\mathrm{N}$ & & 5517 & & & 2018 & \\
\hline \multicolumn{7}{|l|}{ Richer Specification: } \\
\hline Observed Distribution & 0.263 & 0.453 & 0.284 & 0.326 & 0.361 & 0.314 \\
\hline Predicted Distribution & 0.226 & 0.580 & 0.195 & 0.300 & 0.578 & 0.122 \\
\hline \multicolumn{7}{|l|}{ Marginal effects: } \\
\hline Mean & -0.0561 & -0.0882 & 0.1443 & 0.0896 & -0.1907 & 0.1011 \\
\hline Standard Deviation & 0.0289 & 0.0904 & 0.0789 & 0.0735 & 0.0602 & 0.0912 \\
\hline \multirow[t]{2}{*}{ At $\bar{x}$} & -0.0863 & -0.0843 & 0.1706 & 0.1375 & -0.2262 & 0.0887 \\
\hline & $(0.0284)$ & $(0.0394)$ & $(0.0394)$ & $(0.0575)$ & $(0.0535)$ & $(0.0454)$ \\
\hline Proportion Positive & 0.000 & 0.256 & 1.000 & 0.8689 & 0.0000 & 1.0000 \\
\hline IIA Test: P-value & 0.5971 & 0.6386 & 0.8728 & 0.5744 & 0.7252 & 0.2793 \\
\hline Log-likelihood & & -4152.9694 & & & -1268.07 & \\
\hline $\mathrm{N}$ & & 5322 & & & 1831 & \\
\hline
\end{tabular}

Note: Data from PISA 2003. Standard errors in parentheses robust to clusters at school level. It is reported the impact of father or/and mother completing a tertiary level degree. Estimates are from Multinomial logit weighted by stratification weight reported by PISA. Complete results in Appendix. 
Table 2b: Marginal Effect of at least one Parent with College on Secondary School Track Choice. MNL Model - Females

\begin{tabular}{|c|c|c|c|c|c|c|}
\hline & \multicolumn{3}{|c|}{ Italy } & \multicolumn{3}{|c|}{ Germany } \\
\hline & Vocational & Technical & Academic & Vocational & Technical & Academic \\
\hline \multicolumn{7}{|l|}{ Basic Specification: } \\
\hline Observed Distribution & 0.238 & 0.273 & 0.489 & 0.260 & 0.366 & 0.374 \\
\hline Predicted Distribution & 0.184 & 0.308 & 0.508 & 0.238 & 0.512 & 0.250 \\
\hline \multicolumn{7}{|l|}{ Marginal effects: } \\
\hline Mean & -0.1409 & -0.2014 & 0.3422 & -0.1147 & -0.1157 & 0.2304 \\
\hline Standard Deviation & 0.0505 & 0.0464 & 0.0286 & 0.0459 & 0.1339 & 0.1285 \\
\hline \multirow[t]{2}{*}{ At $\bar{x}$} & -0.1517 & -0.2070 & 0.3587 & -0.1643 & -0.1697 & 0.3340 \\
\hline & $(0.0256)$ & $(0.0324)$ & $(0.0369)$ & $(0.0352)$ & $(0.0552)$ & $(0.0631)$ \\
\hline Proportion Positive & 0.0000 & 0.0003 & 1.0000 & 0.0000 & 0.2921 & 1.0000 \\
\hline IIA Test: P-value & 0.9396 & 0.5252 & 0.8104 & 0.7016 & 0.3584 & 0.0038 \\
\hline Log-likelihood & & -5574.72 & & & -1691.27 & \\
\hline $\mathrm{N}$ & & 5973 & & & 2140 & \\
\hline \multicolumn{7}{|l|}{ Richer Specification: } \\
\hline Observed Distribution & 0.236 & 0.272 & 0.492 & 0.229 & 0.377 & 0.394 \\
\hline Predicted Distribution & 0.178 & 0.306 & 0.516 & 0.190 & 0.562 & 0.249 \\
\hline \multicolumn{7}{|l|}{ Marginal effects: } \\
\hline Mean & -0.1167 & -0.0549 & 0.1715 & -0.0106 & -0.1147 & 0.1253 \\
\hline Standard Deviation & 0.0519 & 0.0443 & 0.0363 & 0.0188 & 0.0686 & 0.0846 \\
\hline \multirow[t]{2}{*}{ At $\bar{x}$} & -0.1243 & -0.0756 & 0.1999 & -0.0340 & -0.1568 & 0.1908 \\
\hline & $(0.0235)$ & $(0.0316)$ & $(0.0352)$ & $(0.0348)$ & $(0.0581)$ & $(0.0675)$ \\
\hline Proportion Positive & 0.0000 & 0.1313 & 1.0000 & 0.2629 & 0.0000 & 1.0000 \\
\hline IIA Test: P-value & 0.8617 & 0.7606 & 0.8203 & 0.5697 & 0.3101 & 0.2529 \\
\hline Log-likelihood & & -5189.93 & & & -1430.98 & \\
\hline $\mathrm{N}$ & & 5895 & & & 1974 & \\
\hline
\end{tabular}

Note: See previous table. 
Table 3: Aspirations: marginal effect on intention to procceed further in education

\begin{tabular}{|c|c|c|c|c|}
\hline \multirow[b]{2}{*}{ Specification: } & \multicolumn{2}{|c|}{ Italy } & \multicolumn{2}{|c|}{ Germany } \\
\hline & Basic & Richer & Basic & Richer \\
\hline \multicolumn{5}{|l|}{ Males } \\
\hline \multirow[t]{2}{*}{ highest education in couple upper secondary } & 0.131 & 0.073 & -0.033 & -0.08 \\
\hline & $(0.035)$ & $(0.034)$ & $(0.061)$ & $(0.074)$ \\
\hline \multirow[t]{2}{*}{ highest education in couple tertiary } & 0.222 & 0.116 & 0.161 & 0.056 \\
\hline & $(0.032)$ & $(0.035)$ & $(0.057)$ & $(0.074)$ \\
\hline \multirow[t]{2}{*}{ mother is highest in education } & -0.062 & -0.045 & -0.034 & 0.004 \\
\hline & $(0.026)$ & $(0.028)$ & $(0.034)$ & $(0.039)$ \\
\hline \multirow{2}{*}{ ability (mathematics) } & 0.001 & -0.001 & 0.001 & 0 \\
\hline & $(0.000)$ & $(0.000)$ & $(0.000)$ & $(0.001)$ \\
\hline \multirow[t]{2}{*}{ attending technical school } & 0.239 & 0.22 & 0.141 & 0.083 \\
\hline & $(0.038)$ & $(0.040)$ & $(0.058)$ & $(0.071)$ \\
\hline \multirow[t]{2}{*}{ attending high school } & 0.667 & 0.628 & 0.295 & 0.23 \\
\hline & $(0.024)$ & $(0.029)$ & $(0.057)$ & $(0.073)$ \\
\hline $\mathrm{N}$ & 5341 & 5168 & 1094 & 1012 \\
\hline Pseudo R-squared & 0.33 & 0.35 & 0.11 & 0.16 \\
\hline Log likelihood & -2488.11 & -2314.41 & -654.07 & -575.97 \\
\hline \multicolumn{5}{|l|}{ Females } \\
\hline \multirow{3}{*}{ highest education in couple upper secondary } & Basic & Richer & Basic & Richer \\
\hline & 0.079 & 0.02 & -0.021 & 0.042 \\
\hline & $(0.020)$ & $(0.023)$ & $(0.069)$ & $(0.075)$ \\
\hline \multirow[t]{2}{*}{ highest education in couple tertiary } & 0.158 & 0.052 & 0.142 & 0.139 \\
\hline & $(0.021)$ & $(0.027)$ & $(0.072)$ & $(0.076)$ \\
\hline \multirow[t]{2}{*}{ mother is highest in education } & -0.026 & -0.002 & 0.078 & 0.083 \\
\hline & $(0.02)$ & $(0.019)$ & $(0.041)$ & $(0.041)$ \\
\hline \multirow[t]{2}{*}{ ability (mathematics) } & 0.001 & 0 & 0.001 & -0.001 \\
\hline & $(0.000)$ & 0 & $(0.000)$ & 0 \\
\hline \multirow[t]{2}{*}{ attending technical school } & 0.077 & 0.077 & -0.041 & -0.086 \\
\hline & $(0.035)$ & $(0.033)$ & $(0.073)$ & $(0.08)$ \\
\hline \multirow[t]{2}{*}{ attending high school } & 0.465 & 0.435 & 0.174 & 0.123 \\
\hline & $(0.035)$ & $(0.035)$ & $(0.068)$ & $(0.077)$ \\
\hline $\mathrm{N}$ & 5866 & 5759 & 1356 & 1279 \\
\hline Pseudo R-squared & 0.26 & 0.29 & 0.12 & 0.17 \\
\hline Log likelihood & -2736.95 & -2565.82 & -784.59 & -699.73 \\
\hline
\end{tabular}

Notes: PISA 2003. Robust standard errors in brackets, clusters on schools. * significant at 5\%; ** significant at $1 \%$. Weighed using student sample size. Dependent variable $=1$ if the student declear $\mathrm{s} /$ he intend to proceed further to tertiary education. The basic estimates control for age. The richer version controls for foreign, family situation, occupational prestige, availability of books and previous educational career. 
Table 4a: Marginal Effect of at least one Parent with College on Post-Secondary School Choice - Male Sample, Italy

\begin{tabular}{|c|c|c|c|c|c|c|}
\hline & \multicolumn{3}{|c|}{ Without Tracks } & \multicolumn{3}{|c|}{ With Tracks } \\
\hline & $\begin{array}{c}\text { Never } \\
\text { Enrolled }\end{array}$ & $\begin{array}{l}\text { Drop- } \\
\text { out }\end{array}$ & Enrolled & $\begin{array}{c}\text { Never } \\
\text { Enrolled }\end{array}$ & $\begin{array}{l}\text { Drop- } \\
\text { out }\end{array}$ & Enrolled \\
\hline \multicolumn{7}{|l|}{ Sequential Logit } \\
\hline \multicolumn{7}{|l|}{ Basic Specification: } \\
\hline Observed Distribution & 0.6503 & 0.0580 & 0.2918 & 0.6503 & 0.0580 & 0.2918 \\
\hline $\begin{array}{l}\text { Predicted Distribution } \\
\text { Marginal Effects: }\end{array}$ & 0.6692 & 0.0655 & 0.2653 & 0.6595 & 0.0713 & 0.2692 \\
\hline Mean & -0.4584 & 0.0119 & 0.4465 & -0.3035 & 0.0202 & 0.2833 \\
\hline Standard Deviation & 0.0891 & 0.0261 & 0.0737 & 0.0900 & 0.0245 & 0.0789 \\
\hline At $\bar{x}$ & $\begin{array}{l}-0.5187 \\
(0.0135)\end{array}$ & $\begin{array}{c}0.0097 \\
(0.0116)\end{array}$ & $\begin{array}{c}0.5090 \\
(0.0190)\end{array}$ & $\begin{array}{l}-0.3841 \\
(0.0266)\end{array}$ & $\begin{array}{c}0.0200 \\
(0.0125)\end{array}$ & $\begin{array}{c}0.3641 \\
(0.0281)\end{array}$ \\
\hline Proportion Positive & 0.0000 & 0.6837 & 1.0000 & 0.0000 & 0.8027 & 1.0000 \\
\hline Log-likelihood & & -6707.97 & & & -6269.49 & \\
\hline $\mathrm{N}$ & & 9956 & & & 9956 & \\
\hline $\begin{array}{l}\text { Richer Specification: } \\
\text { Observed Distribution }\end{array}$ & 0.6501 & 0.0579 & 0.2921 & 0.6501 & 0.0579 & 0.2921 \\
\hline $\begin{array}{l}\text { Predicted Distribution } \\
\text { Marginal Effects: }\end{array}$ & 0.6770 & 0.0661 & 0.2570 & 0.6693 & 0.0728 & 0.2579 \\
\hline Mean & -0.4491 & 0.0069 & 0.4421 & -0.3082 & 0.0137 & 0.2945 \\
\hline Standard Deviation & 0.0194 & 0.0124 & 0.0212 & 0.0238 & 0.0116 & 0.0274 \\
\hline At $\bar{x}$ & $\begin{array}{l}-0.3700 \\
(0.0857)\end{array}$ & $\begin{array}{c}0.0075 \\
(0.0255)\end{array}$ & $\begin{array}{c}0.3625 \\
(0.0806)\end{array}$ & $\begin{array}{l}-0.2202 \\
(0.0809)\end{array}$ & $\begin{array}{c}0.0121 \\
(0.0217)\end{array}$ & $\begin{array}{c}0.2082 \\
(0.0769)\end{array}$ \\
\hline Proportion Positive & 0.0000 & 0.6305 & 1.0000 & 0.0000 & 0.7255 & 1.0000 \\
\hline Log-likelihood & & -6813.91 & & & -6270.32 & \\
\hline $\mathrm{N}$ & & 10453 & & & 10453 & \\
\hline Multinomial Logit & & & & & & \\
\hline $\begin{array}{l}\text { Basic Specification: } \\
\text { Test IIA: P-value }\end{array}$ & 0.4175 & 0.4164 & 0.3614 & 0.1008 & 0.4633 & 0.0809 \\
\hline Marginal Effects: & & & & & & \\
\hline At $\bar{x}$ & $\begin{array}{l}-0.5226 \\
(0.0156)\end{array}$ & $\begin{array}{c}0.0103 \\
(0.0104)\end{array}$ & $\begin{array}{c}0.5123 \\
(0.0178)\end{array}$ & $\begin{array}{l}-0.3860 \\
(0.0228)\end{array}$ & $\begin{array}{c}0.0214 \\
(0.0131)\end{array}$ & $\begin{array}{c}0.3646 \\
(0.0239)\end{array}$ \\
\hline $\begin{array}{l}\text { Richer Specification: } \\
\text { Test IIA: P-value } \\
\text { Marginal Effects: }\end{array}$ & 0.8554 & 0.5009 & 0.529 & 0.7656 & 0.0443 & 0.3669 \\
\hline At $\bar{x}$ & $\begin{array}{l}-0.4527 \\
(0.0204)\end{array}$ & $\begin{array}{c}0.0069 \\
(0.0111) \\
\end{array}$ & $\begin{array}{c}0.4458 \\
(0.0221)\end{array}$ & $\begin{array}{l}-0.3092 \\
(0.0273)\end{array}$ & $\begin{array}{c}0.0156 \\
(0.0136)\end{array}$ & $\begin{array}{c}0.2937 \\
(0.0276) \\
\end{array}$ \\
\hline
\end{tabular}

Notes: Dependent variable $=1$ Never Enrolled; $=2$ Dropped-out; $=3$ Still Enrolled after three years. Richer specification includes controls for: family background, demographic characteristics, ability (grades). Bootstrap standard errors in parentheses. 
Table 4b: Marginal Effect of at least one Parent with College on Post-Secondary School Choice - Female Sample, Italy

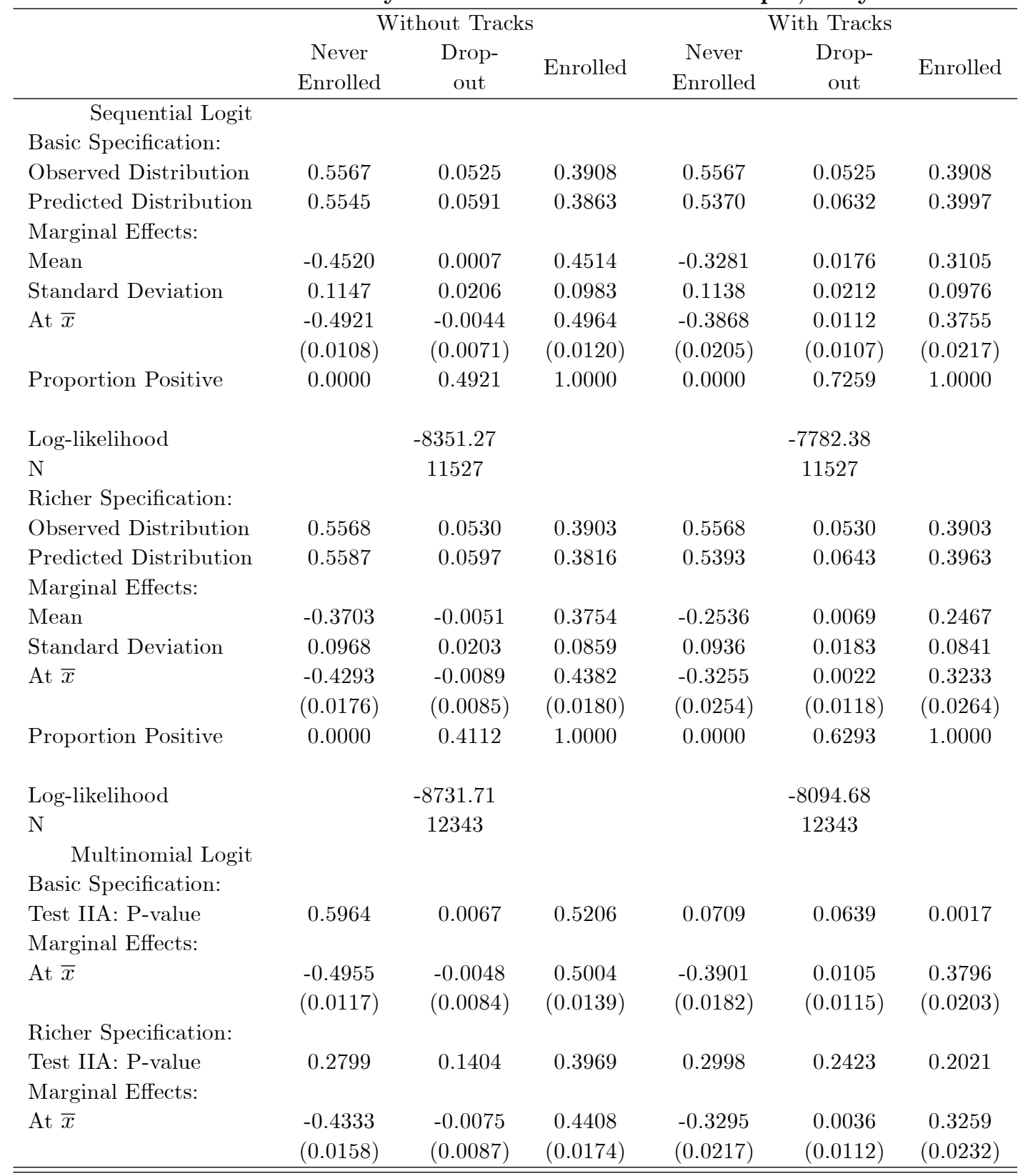

Notes: see Table 4a. 
Table 5a: Marginal Effect of at least one Parent with Academic Secondary School degree (Abitur) on Post-Secondary School Choice MNL Model - Male Sample, Germany

\begin{tabular}{|c|c|c|c|c|c|c|}
\hline & \multicolumn{3}{|c|}{ Without Tracks } & \multicolumn{3}{|c|}{ With Tracks } \\
\hline & Never & Enrolled & Enrolled & Never & Enrolled & Enrolled \\
\hline & Enrolled & Vocat. & Univ. & Enrolled & Vocat. & Univ. \\
\hline Observed Distr. & 0.0749 & 0.5802 & 0.3449 & 0.0749 & 0.5802 & 0.3449 \\
\hline Predicted Distr. & 0.0527 & 0.6148 & 0.3325 & 0.0851 & 0.7607 & 0.1744 \\
\hline \multicolumn{7}{|l|}{ Marginal Effects: } \\
\hline Mean & 0.1030 & -0.3918 & 0.2887 & 0.0631 & -0.3108 & 0.248 \\
\hline Standard Dev. & 0.0760 & 0.0534 & 0.0634 & 0.0756 & 0.1885 & 0.2351 \\
\hline \multirow[t]{2}{*}{ At $\bar{x}$} & 0.0724 & -0.4304 & 0.3580 & 0.1029 & -0.2199 & 0.1171 \\
\hline & $(0.0421)$ & $(0.0684)$ & $(0.0756)$ & $(0.0650)$ & $(0.0899)$ & $(0.0765)$ \\
\hline Proportion Pos. & 1.000 & 0.000 & 1.000 & 0.847 & 0.000 & 0.992 \\
\hline IIA Test: P-value & 0.4956 & 0.8271 & 0.4778 & 0.4696 & 0.4591 & 0.8044 \\
\hline Log-likelihood & & -266.45 & & & -202.430 & \\
\hline $\mathrm{N}$ & & 373 & & & 373 & \\
\hline
\end{tabular}

Notes: Data from GSOEP 2001 and 2002. Dependent variable is: $=1$ if enrolled in University or completed a University degree; $=2$ if enrolled or completed a Post-secondary vocational degree or Apprenticeship; $=3$ if never enrolled in any Post-secondary degree. Asymptotic standard errors in parentheses. Complete results in Appendix. 
Table 5b: Marginal Effect of at least one Parent with Academic Secondary School degree (Abitur) on Post-Secondary School Choice MNL Model - Female Sample, Germany

\begin{tabular}{|c|c|c|c|c|c|c|}
\hline & \multicolumn{3}{|c|}{ Without Tracks } & \multicolumn{3}{|c|}{ With Tracks } \\
\hline & $\begin{array}{c}\text { Never } \\
\text { Enrolled }\end{array}$ & $\begin{array}{c}\text { Enrolled } \\
\text { Vocat. }\end{array}$ & $\begin{array}{c}\text { Enrolled } \\
\text { Univ. }\end{array}$ & $\begin{array}{c}\text { Never } \\
\text { Enrolled }\end{array}$ & $\begin{array}{c}\text { Enrolled } \\
\text { Vocat. }\end{array}$ & $\begin{array}{c}\text { Enrolled } \\
\text { Univ. }\end{array}$ \\
\hline Observed Distr. & 0.0471 & 0.5882 & 0.3647 & 0.0471 & 0.5882 & 0.3647 \\
\hline Predicted Distr. & 0.0405 & 0.6155 & 0.3439 & 0.0122 & 0.7297 & 0.2581 \\
\hline \multicolumn{7}{|l|}{ Marginal Effects: } \\
\hline Mean & 0.0183 & -0.4227 & 0.4043 & 0.0444 & -0.2823 & 0.2380 \\
\hline Standard Dev. & 0.0241 & 0.0423 & 0.0571 & 0.0505 & 0.1248 & 0.1595 \\
\hline \multirow[t]{2}{*}{ At $\bar{x}$} & 0.0064 & -0.4709 & 0.4645 & 0.0139 & -0.3258 & 0.3119 \\
\hline & $(0.0216)$ & $(0.0583)$ & $(0.0096)$ & $(0.0124)$ & $(0.0765)$ & $(0.0769)$ \\
\hline Proportion Pos. & 0.831 & 0.000 & 1.000 & 0.903 & 0.000 & 1.000 \\
\hline IIA Test: P-value & 0.8924 & 0.9731 & 0.7442 & 0.0000 & 0.5535 & 0.5962 \\
\hline Log-likelihood & & -292.90 & & & -235.92 & \\
\hline $\mathrm{N}$ & & 425 & & & 425 & \\
\hline
\end{tabular}

Notes: See Table 5a. 


\section{Appendix}

Table A.1: Definition of variables in PISA sample

\begin{tabular}{lc}
\hline Definition & Variable Name \\
\hline female & female \\
age (months) & age \\
foreign born & foreign \\
speaking dialect at home & dialect \\
combined score in mathematical test & combmath \\
combined score in reading test & combread \\
combined score in science test & combscie \\
combined score in problem solvingtest & combprob \\
slower than usual in completing grades & regular1 \\
regular in completing grades & regular2 \\
faster than usual in completing grades & regular 3 \\
failed at least once & failed \\
highest parents completed primary & histedaggr1 \\
highest parents completed secondary & histedaggr2 \\
highest parents completed tertiary & histedaggr3 \\
mother is highest & mhist \\
parents living together & intact \\
highest parents socio-economic status & hisei \\
mother currently housewife & housewife \\
less than 25 books at home & books1 \\
between 25 and 200 books at home & books2 \\
more than 200 books at home & books3 \\
vocational school & type1 \\
technical school & type2 \\
high school & type3 \\
\hline
\end{tabular}


Tab A.2a: Descriptive Statistics PISA sample - Italy

\begin{tabular}{|c|c|c|c|c|c|c|}
\hline variable name & $\begin{array}{l}\text { full sample } \\
\text { wgh.mean }\end{array}$ & $\mathrm{sd}$ & $\begin{array}{l}\text { male } \\
\text { wgh.mean }\end{array}$ & $\mathrm{sd}$ & $\begin{array}{l}\text { female } \\
\text { wgh.mean }\end{array}$ & $\mathrm{sd}$ \\
\hline female & 0.529 & 0.499 & & & & \\
\hline age & 15.707 & 0.285 & 15.699 & 0.283 & 15.714 & 0.287 \\
\hline foreign & 0.025 & 0.157 & 0.025 & 0.155 & 0.026 & 0.158 \\
\hline dialect & 0.154 & 0.361 & 0.190 & 0.392 & 0.122 & 0.327 \\
\hline combmath & 469.438 & 89.860 & 481.162 & 94.093 & 459.014 & 84.575 \\
\hline combread & 480.244 & 91.115 & 461.358 & 95.926 & 497.037 & 83.090 \\
\hline combscie & 491.497 & 97.081 & 497.471 & 102.266 & 486.186 & 91.908 \\
\hline combprob & 474.505 & 92.385 & 475.324 & 98.990 & 473.777 & 86.089 \\
\hline regular1 & 0.139 & 0.346 & 0.187 & 0.390 & 0.096 & 0.295 \\
\hline regular2 & 0.817 & 0.387 & 0.779 & 0.415 & 0.850 & 0.357 \\
\hline regular 3 & 0.044 & 0.206 & 0.034 & 0.182 & 0.053 & 0.225 \\
\hline failed & 0.109 & 0.311 & 0.150 & 0.358 & 0.071 & 0.258 \\
\hline histedaggr1 & 0.284 & 0.451 & 0.268 & 0.443 & 0.299 & 0.458 \\
\hline histedaggr2 & 0.364 & 0.481 & 0.344 & 0.475 & 0.382 & 0.486 \\
\hline histedaggr3 & 0.352 & 0.477 & 0.388 & 0.487 & 0.319 & 0.466 \\
\hline mhist & 0.233 & 0.423 & 0.241 & 0.428 & 0.226 & 0.418 \\
\hline intact & 0.791 & 0.407 & 0.790 & 0.408 & 0.791 & 0.406 \\
\hline hisei & 47.093 & 16.695 & 47.387 & 16.926 & 46.831 & 16.485 \\
\hline housewife & 0.365 & 0.482 & 0.349 & 0.477 & 0.381 & 0.486 \\
\hline books1 & 0.247 & 0.431 & 0.265 & 0.442 & 0.231 & 0.422 \\
\hline books2 & 0.526 & 0.499 & 0.501 & 0.500 & 0.549 & 0.498 \\
\hline books3 & 0.213 & 0.409 & 0.217 & 0.412 & 0.210 & 0.407 \\
\hline type1 & 0.246 & 0.430 & 0.282 & 0.450 & 0.213 & 0.410 \\
\hline type2 & 0.346 & 0.476 & 0.415 & 0.493 & 0.284 & 0.451 \\
\hline type3 & 0.409 & 0.492 & 0.303 & 0.459 & 0.503 & 0.500 \\
\hline $\mathrm{N}$ & \multicolumn{2}{|c|}{11181} & \multicolumn{2}{|c|}{5322} & \multicolumn{2}{|c|}{5859} \\
\hline
\end{tabular}


Table A.2b - Descriptive Statistics PISA sample - Germany

\begin{tabular}{|c|c|c|c|c|c|c|}
\hline variable name & $\begin{array}{l}\text { full sample } \\
\text { wgh.mean }\end{array}$ & sd & $\begin{array}{c}\text { male } \\
\text { wgh.mean }\end{array}$ & sd & $\begin{array}{c}\text { female } \\
\text { wgh.mean }\end{array}$ & sd \\
\hline female & 0.517 & 0.500 & & & & \\
\hline age & 15.769 & 0.283 & 15.777 & 0.279 & 15.762 & 0.287 \\
\hline foreign & 0.080 & 0.271 & 0.079 & 0.270 & 0.081 & 0.273 \\
\hline dialect & 0.000 & 0.000 & 0.000 & 0.000 & 0.000 & 0.000 \\
\hline combmath & 520.639 & 91.320 & 528.516 & 93.047 & 513.733 & 88.665 \\
\hline combread & 512.201 & 91.839 & 493.870 & 94.774 & 529.689 & 85.358 \\
\hline combscie & 522.689 & 96.135 & 529.274 & 98.336 & 517.124 & 93.173 \\
\hline combprob & 528.354 & 85.206 & 527.696 & 87.817 & 529.371 & 82.272 \\
\hline regular1 & 0.135 & 0.342 & 0.157 & 0.364 & 0.115 & 0.319 \\
\hline regular2 & 0.612 & 0.487 & 0.618 & 0.486 & 0.280 & 0.449 \\
\hline regular 3 & 0.252 & 0.434 & 0.224 & 0.417 & 0.280 & 0.449 \\
\hline failed & 0.126 & 0.332 & 0.138 & 0.345 & 0.114 & 0.318 \\
\hline histedaggr1 & 0.135 & 0.342 & 0.144 & 0.351 & 0.127 & 0.333 \\
\hline histedaggr2 & 0.437 & 0.496 & 0.408 & 0.492 & 0.465 & 0.499 \\
\hline histedaggr3 & 0.428 & 0.495 & 0.449 & 0.497 & 0.408 & 0.492 \\
\hline mhist & 0.172 & 0.377 & 0.179 & 0.383 & 0.165 & 0.371 \\
\hline intact & 0.754 & 0.431 & 0.766 & 0.424 & 0.744 & 0.437 \\
\hline hisei & 50.041 & 16.219 & 50.260 & 16.341 & 49.906 & 16.078 \\
\hline housewife & 0.204 & 0.403 & 0.200 & 0.400 & 0.208 & 0.406 \\
\hline books1 & 0.176 & 0.381 & 0.195 & 0.396 & 0.156 & 0.363 \\
\hline books2 & 0.505 & 0.500 & 0.503 & 0.500 & 0.507 & 0.500 \\
\hline books3 & 0.311 & 0.463 & 0.293 & 0.455 & 0.329 & 0.470 \\
\hline type1 & 0.302 & 0.459 & 0.351 & 0.477 & 0.253 & 0.435 \\
\hline type2 & 0.359 & 0.480 & 0.350 & 0.477 & 0.370 & 0.483 \\
\hline type3 & 0.339 & 0.474 & 0.299 & 0.458 & 0.377 & 0.485 \\
\hline $\mathrm{N}$ & 3840 & & 1831 & & 1974 & \\
\hline
\end{tabular}


Table A.3a: Choice of Secondary School Track: Complete Results - Male

\begin{tabular}{|c|c|c|c|c|c|c|c|c|}
\hline & \multicolumn{4}{|c|}{ Italy } & \multicolumn{4}{|c|}{ Germany } \\
\hline & \multicolumn{2}{|c|}{ Basic (5517) } & \multicolumn{2}{|c|}{ Richer (5322) } & \multicolumn{2}{|c|}{ Basic (2018) } & \multicolumn{2}{|c|}{ Richer (1831) } \\
\hline & $\begin{array}{c}\text { Log-lik= } \\
\text { Coef. }\end{array}$ & $\begin{array}{l}-4761.34 \\
\text { Std. Err. }\end{array}$ & $\begin{array}{c}\text { Log-lik= } \\
\text { Coef. }\end{array}$ & $\begin{array}{l}-4152.97 \\
\text { Std. Err. }\end{array}$ & $\begin{array}{c}\text { Log-lik= } \\
\text { Coef. }\end{array}$ & $\begin{array}{l}-1545.99 \\
\text { Std. Err. }\end{array}$ & $\begin{array}{c}\text { Log-lik= } \\
\text { Coef. }\end{array}$ & $\begin{array}{l}-1268.07 \\
\text { Std. Err. }\end{array}$ \\
\hline Technical & & & & & & & & \\
\hline age & 0.073 & 0.171 & 0.015 & 0.180 & -0.067 & 0.264 & 0.299 & 0.305 \\
\hline foreign & & & -0.741 & 0.322 & & & 0.836 & 0.328 \\
\hline dialect & & & -0.488 & 0.230 & & & & \\
\hline combmath & 0.012 & 0.002 & 0.006 & 0.002 & 0.013 & 0.002 & 0.003 & 0.003 \\
\hline combread & & & 0.003 & 0.001 & & & 0.008 & 0.002 \\
\hline combscie & & & 0.001 & 0.001 & & & 0.000 & 0.002 \\
\hline combprob & & & 0.003 & 0.002 & & & 0.005 & 0.003 \\
\hline regular1 & & & -0.366 & 0.649 & & & 0.476 & 0.373 \\
\hline regular2 & & & -0.176 & 0.629 & & & 0.119 & 0.274 \\
\hline failed & & & -0.058 & 0.199 & & & 0.146 & 0.206 \\
\hline histedaggr2 & 0.132 & 0.151 & -0.019 & 0.153 & -0.196 & 0.216 & -0.365 & 0.239 \\
\hline histedaggr3 & 0.435 & 0.174 & 0.255 & 0.168 & -0.282 & 0.230 & -0.863 & 0.263 \\
\hline mhist & 0.160 & 0.133 & 0.063 & 0.138 & -0.205 & 0.151 & -0.396 & 0.170 \\
\hline intact & & & 0.441 & 0.120 & & & 0.119 & 0.177 \\
\hline hisei & & & 0.007 & 0.005 & & & 0.024 & 0.006 \\
\hline housewife & & & 0.192 & 0.165 & & & 0.195 & 0.204 \\
\hline books2 & & & -0.048 & 0.135 & & & 0.060 & 0.183 \\
\hline books3 & & & 0.037 & 0.182 & & & 0.755 & 0.250 \\
\hline $\begin{array}{l}\text { constant } \\
\text { Academic }\end{array}$ & -6.550 & 2.823 & -5.824 & 3.073 & -4.888 & 4.174 & -13.455 & 5.298 \\
\hline age & 0.349 & 0.221 & 0.268 & 0.249 & -0.932 & 0.330 & -0.403 & 0.455 \\
\hline foreign & & & -0.852 & 0.500 & & & 1.340 & 0.593 \\
\hline dialect & & & -0.882 & 0.278 & & & & \\
\hline combmath & 0.021 & 0.002 & 0.004 & 0.002 & 0.035 & 0.002 & 0.017 & 0.004 \\
\hline combread & & & 0.008 & 0.002 & & & 0.022 & 0.003 \\
\hline combscie & & & 0.002 & 0.002 & & & 0.000 & 0.003 \\
\hline combprob & & & 0.008 & 0.002 & & & 0.004 & 0.005 \\
\hline regular1 & & & -1.940 & 0.682 & & & 1.379 & 0.521 \\
\hline regular2 & & & -0.768 & 0.611 & & & 0.502 & 0.339 \\
\hline failed & & & -0.111 & 0.337 & & & -0.511 & 0.382 \\
\hline histedaggr2 & 1.190 & 0.215 & 0.495 & 0.239 & 0.110 & 0.339 & 0.069 & 0.421 \\
\hline histedaggr3 & 2.440 & 0.231 & 1.203 & 0.235 & 1.074 & 0.339 & 0.251 & 0.446 \\
\hline mhist & 0.587 & 0.151 & 0.377 & 0.165 & 0.385 & 0.207 & 0.069 & 0.240 \\
\hline intact & & & 0.569 & 0.195 & & & 0.245 & 0.224 \\
\hline hisei & & & 0.046 & 0.006 & & & 0.052 & 0.007 \\
\hline housewife & & & 0.367 & 0.192 & & & 0.311 & 0.277 \\
\hline books2 & & & 0.611 & 0.171 & & & 0.094 & 0.326 \\
\hline books3 & & & 0.927 & 0.232 & & & 1.054 & 0.374 \\
\hline constant & -17.226 & 3.682 & -17.769 & 4.198 & -5.287 & 5.056 & -19.917 & 7.452 \\
\hline
\end{tabular}


Table A.3b: Choice of Secondary School Track: Complete Results - Female

\begin{tabular}{|c|c|c|c|c|c|c|c|c|}
\hline & \multicolumn{4}{|c|}{ Italy } & \multicolumn{4}{|c|}{ Germany } \\
\hline & \multicolumn{2}{|c|}{ Basic (5973) } & \multicolumn{2}{|c|}{ Richer (5859) } & \multicolumn{2}{|c|}{ Basic (2140) } & \multicolumn{2}{|c|}{ Richer (1974) } \\
\hline & $\begin{array}{c}\text { Log-lik= } \\
\text { Coef. }\end{array}$ & $\begin{array}{l}-5574.72 \\
\text { Std. Err. }\end{array}$ & $\begin{array}{c}\text { Log-lik= } \\
\text { Coef. }\end{array}$ & $\begin{array}{l}-5189.93 \\
\text { Std. Err. }\end{array}$ & $\begin{array}{c}\text { Log-lik= } \\
\text { Coef. }\end{array}$ & $\begin{array}{c}-1691.2 \\
\text { Std. Err. }\end{array}$ & $\begin{array}{c}\text { Log-lik= } \\
\text { Coef. }\end{array}$ & $\begin{array}{l}-1430.98 \\
\text { Std. Err }\end{array}$ \\
\hline Technical & & & & & & & & \\
\hline age & -0.033 & 0.248 & -0.211 & 0.251 & -0.350 & 0.261 & -0.336 & 0.330 \\
\hline foreign & & & 0.507 & 0.348 & & & 0.933 & 0.388 \\
\hline dialect & & & 0.019 & 0.288 & & & & \\
\hline combmath & 0.007 & 0.002 & 0.003 & 0.002 & 0.011 & 0.002 & 0.004 & 0.003 \\
\hline combread & & & 0.004 & 0.002 & & & 0.007 & 0.002 \\
\hline combscie & & & 0.002 & 0.001 & & & -0.001 & 0.003 \\
\hline combprob & & & 0.000 & 0.002 & & & 0.004 & 0.003 \\
\hline regular1 & & & -0.688 & 0.579 & & & -0.014 & 0.378 \\
\hline regular2 & & & -0.241 & 0.501 & & & -0.211 & 0.241 \\
\hline failed & & & 0.431 & 0.236 & & & 0.517 & 0.250 \\
\hline histedaggr2 & 0.200 & 0.160 & 0.427 & 0.149 & 0.100 & 0.187 & -0.120 & 0.222 \\
\hline histedaggr3 & 0.206 & 0.190 & 0.540 & 0.192 & 0.420 & 0.206 & -0.106 & 0.223 \\
\hline mhist & -0.109 & 0.156 & 0.089 & 0.164 & 0.145 & 0.171 & 0.063 & 0.196 \\
\hline intact & & & 0.156 & 0.170 & & & 0.161 & 0.176 \\
\hline hisei & & & -0.002 & 0.006 & & & 0.017 & 0.005 \\
\hline housewife & & & 0.504 & 0.173 & & & 0.066 & 0.196 \\
\hline books2 & & & -0.349 & 0.143 & & & 0.264 & 0.198 \\
\hline books3 & & & -0.672 & 0.238 & & & 0.560 & 0.267 \\
\hline $\begin{array}{l}\text { constant } \\
\text { Academic }\end{array}$ & -2.214 & 3.794 & -0.551 & 4.040 & 0.250 & 4.125 & -2.047 & 5.528 \\
\hline age & 0.194 & 0.214 & -0.005 & 0.220 & -0.923 & 0.294 & -0.044 & 0.462 \\
\hline foreign & & & 0.079 & 0.454 & & & 1.367 & 0.453 \\
\hline dialect & & & -0.087 & 0.391 & & & & \\
\hline combmath & 0.011 & 0.002 & 0.002 & 0.002 & 0.031 & 0.002 & 0.017 & 0.003 \\
\hline combread & & & 0.009 & 0.002 & & & 0.024 & 0.003 \\
\hline combscie & & & 0.002 & 0.001 & & & -0.003 & 0.003 \\
\hline combprob & & & -0.001 & 0.002 & & & 0.003 & 0.004 \\
\hline regular1 & & & -1.414 & 0.542 & & & 1.550 & 0.514 \\
\hline regular2 & & & -0.425 & 0.429 & & & 0.746 & 0.305 \\
\hline failed & & & 0.381 & 0.273 & & & -0.268 & 0.373 \\
\hline histedaggr2 & 0.981 & 0.167 & 0.780 & 0.148 & 0.718 & 0.310 & 0.313 & 0.355 \\
\hline histedaggr3 & 1.668 & 0.203 & 1.172 & 0.182 & 1.973 & 0.324 & 0.905 & 0.369 \\
\hline mhist & 0.282 & 0.143 & 0.394 & 0.157 & 0.571 & 0.220 & 0.381 & 0.255 \\
\hline intact & & & 0.095 & 0.159 & & & 0.315 & 0.228 \\
\hline hisei & & & 0.016 & 0.006 & & & 0.047 & 0.008 \\
\hline housewife & & & 0.402 & 0.168 & & & -0.289 & 0.260 \\
\hline books2 & & & 0.247 & 0.175 & & & -0.103 & 0.282 \\
\hline books3 & & & 0.493 & 0.258 & & & 0.324 & 0.346 \\
\hline constant & -8.169 & 3.296 & -6.562 & 3.610 & -2.509 & 4.627 & -23.984 & 7.853 \\
\hline
\end{tabular}


Table A.4a: Aspirations (intention to proceed further in education) - Probit - Italy

\begin{tabular}{|c|c|c|c|c|}
\hline & $\begin{array}{c}\text { males } \\
\text { basic }\end{array}$ & $\begin{array}{c}\text { males } \\
\text { extended }\end{array}$ & $\begin{array}{c}\text { females } \\
\text { basic }\end{array}$ & $\begin{array}{l}\text { females } \\
\text { extended }\end{array}$ \\
\hline \multirow[t]{2}{*}{ age } & 0.001 & -0.036 & 0.038 & 0.016 \\
\hline & {$[0.039]$} & {$[0.041]$} & {$[0.028]$} & {$[0.029]$} \\
\hline \multirow[t]{2}{*}{ ability(mathematics) } & 0.001 & -0.001 & 0.001 & 0 \\
\hline & {$[0.000]^{* *}$} & {$[0.000]$} & {$[0.000]^{* *}$} & {$[0.000]$} \\
\hline \multirow[t]{2}{*}{ attending technical school } & 0.239 & 0.22 & 0.077 & 0.077 \\
\hline & {$[0.038]^{* *}$} & {$[0.040]^{* *}$} & {$[0.035]^{*}$} & {$[0.033]^{*}$} \\
\hline \multirow[t]{2}{*}{ attending high school } & 0.667 & 0.628 & 0.465 & 0.435 \\
\hline & {$[0.024]^{* *}$} & {$[0.029]^{* *}$} & {$[0.035]^{* *}$} & {$[0.035]^{* *}$} \\
\hline \multirow[t]{2}{*}{ highest education in the couple (secondary) } & 0.131 & 0.073 & 0.079 & 0.02 \\
\hline & {$[0.035]^{* *}$} & {$[0.034]^{*}$} & {$[0.020]^{* *}$} & {$[0.023]$} \\
\hline \multirow[t]{2}{*}{ highest education in the couple (tertiary) } & 0.222 & 0.116 & 0.158 & 0.052 \\
\hline & {$[0.032]^{* *}$} & {$[0.035]^{* *}$} & {$[0.021]^{* *}$} & {$[0.027]$} \\
\hline \multirow[t]{2}{*}{ mother is highest in education } & -0.062 & -0.045 & -0.026 & -0.002 \\
\hline & {$[0.026]^{*}$} & {$[0.028]$} & {$[0.020]$} & {$[0.019]$} \\
\hline \multirow[t]{2}{*}{ foreign born } & & 0.078 & & 0.074 \\
\hline & & {$[0.068]$} & & {$[0.060]$} \\
\hline \multirow[t]{2}{*}{ ability(reading) } & & 0.001 & & 0.001 \\
\hline & & {$[0.000]$} & & {$[0.000]^{*}$} \\
\hline \multirow[t]{2}{*}{ ability(science) } & & 0.001 & & 0 \\
\hline & & {$[0.000]^{* *}$} & & {$[0.000]$} \\
\hline \multirow[t]{2}{*}{ ability(problem solving) } & & 0 & & 0 \\
\hline & & {$[0.000]$} & & {$[0.000]$} \\
\hline \multirow[t]{2}{*}{ earlier in age of enrolment } & & -0.264 & & -0.34 \\
\hline & & {$[0.074]^{* *}$} & & {$[0.071]^{* *}$} \\
\hline \multirow[t]{2}{*}{ regular in age of enrolment } & & -0.187 & & -0.148 \\
\hline & & {$[0.060]^{* *}$} & & {$[0.032]^{* *}$} \\
\hline \multirow[t]{2}{*}{ failed } & & -0.042 & & 0.016 \\
\hline & & {$[0.065]$} & & {$[0.040]$} \\
\hline \multirow[t]{2}{*}{ intact family } & & -0.011 & & 0.021 \\
\hline & & {$[0.029]$} & & {$[0.023]$} \\
\hline \multirow[t]{2}{*}{ socio-economic index (highest in the couple) } & & 0.003 & & 0.003 \\
\hline & & {$[0.001]^{* *}$} & & {$[0.001]^{* *}$} \\
\hline \multirow[t]{2}{*}{$26-200$ books at home } & & 0.051 & & 0.086 \\
\hline & & {$[0.030]$} & & {$[0.018]^{* *}$} \\
\hline \multirow[t]{2}{*}{ more than 200 books at home } & & 0.166 & & 0.159 \\
\hline & & {$[0.038]^{* *}$} & & {$[0.020]^{* *}$} \\
\hline Observations & 5341 & 5168 & 5866 & 5759 \\
\hline PseudoR-squared & 0.33 & 0.35 & 0.26 & 0.29 \\
\hline Loglikelihood & -2488.11 & -2314.41 & -2736.95 & -2565.82 \\
\hline
\end{tabular}


Table A.4b: Aspirations (intention to proceed further in education) - Probit - Germany

\begin{tabular}{|c|c|c|c|c|}
\hline & males & males & females & females \\
\hline & basic & extended & basic & extended \\
\hline \multirow[t]{2}{*}{ age } & 0 & 0 & 0.074 & 0.028 \\
\hline & {$[0.054]$} & {$[0.081]$} & {$[0.046]$} & {$[0.065]$} \\
\hline \multirow[t]{2}{*}{ ability(mathematics) } & 0.001 & 0 & 0.001 & -0.001 \\
\hline & {$[0.000]$} & {$[0.001]$} & {$[0.000]^{* *}$} & {$[0.000]$} \\
\hline \multirow[t]{2}{*}{ attending technical school } & 0.141 & 0.083 & -0.041 & -0.086 \\
\hline & {$[0.058]^{*}$} & {$[0.071]$} & {$[0.073]$} & {$[0.080]$} \\
\hline \multirow[t]{2}{*}{ attending high school } & 0.295 & 0.23 & 0.174 & 0.123 \\
\hline & {$[0.057]^{* *}$} & {$[0.073]^{* *}$} & {$[0.068]^{*}$} & {$[0.077]$} \\
\hline \multirow[t]{2}{*}{ highest education in the couple (secondary) } & -0.033 & -0.08 & -0.021 & 0.042 \\
\hline & {$[0.061]$} & {$[0.074]$} & {$[0.069]$} & {$[0.075]$} \\
\hline \multirow{2}{*}{ highest education in the couple (tertiary) } & 0.161 & 0.056 & 0.142 & 0.139 \\
\hline & {$[0.057]^{* *}$} & {$[0.074]$} & {$[0.072]^{*}$} & {$[0.076]$} \\
\hline \multirow[t]{2}{*}{ mother is highest in education } & -0.034 & 0.004 & 0.078 & 0.083 \\
\hline & {$[0.034]$} & {$[0.039]$} & {$[0.041]$} & {$[0.041]^{*}$} \\
\hline \multirow[t]{2}{*}{ foreign born } & & 0.127 & & 0.145 \\
\hline & & {$[0.080]$} & & {$[0.065]^{*}$} \\
\hline \multirow[t]{2}{*}{ ability(reading) } & & -0.001 & & -0.001 \\
\hline & & {$[0.001]$} & & {$[0.000]^{*}$} \\
\hline \multirow[t]{2}{*}{ ability(science) } & & 0.004 & & 0.004 \\
\hline & & {$[0.001]^{* *}$} & & {$[0.001]^{* *}$} \\
\hline \multirow[t]{2}{*}{ ability(problem solving) } & & -0.002 & & -0.001 \\
\hline & & {$[0.001]^{* *}$} & & {$[0.001]^{*}$} \\
\hline \multirow[t]{2}{*}{ earlier in age of enrolment } & & 0.048 & & -0.035 \\
\hline & & {$[0.100]$} & & {$[0.078]$} \\
\hline \multirow[t]{2}{*}{ regular in age of enrolment } & & -0.015 & & -0.062 \\
\hline & & {$[0.055]$} & & {$[0.044]$} \\
\hline \multirow[t]{2}{*}{ failed } & & -0.091 & & -0.028 \\
\hline & & {$[0.065]$} & & {$[0.083]$} \\
\hline \multirow[t]{2}{*}{ intact family } & & -0.059 & & 0.026 \\
\hline & & {$[0.042]$} & & {$[0.034]$} \\
\hline \multirow[t]{2}{*}{ socio-economic index (highest in the couple) } & & 0.001 & & 0.002 \\
\hline & & {$[0.001]$} & & {$[0.001]^{*}$} \\
\hline \multirow[t]{2}{*}{$26-200$ books at home } & & -0.012 & & -0.045 \\
\hline & & {$[0.071]$} & & {$[0.055]$} \\
\hline \multirow[t]{2}{*}{ more than 200 books at home } & & 0.088 & & -0.025 \\
\hline & & {$[0.073]$} & & {$[0.055]$} \\
\hline Observations & 1094 & 1012 & 1356 & 1279 \\
\hline PseudoR-squared & 0.11 & 0.16 & 0.12 & 0.17 \\
\hline Loglikelihood & -654.07 & -575.97 & -784.59 & -699.73 \\
\hline
\end{tabular}


Table A.5: Definition of Variables in ISTAT sample

\begin{tabular}{|c|c|}
\hline Definition & Variable Name \\
\hline \multicolumn{2}{|l|}{ Dependent Variable: } \\
\hline Never Enrolled in University & Never Enrolled \\
\hline Drop-out from University & Drop-out \\
\hline Enrolled after 3 years or Completed & Enrolled \\
\hline Highest schooling parents: Primary & parhistschd1 \\
\hline Highest schooling parents: Secondary & parhistschd2 \\
\hline Highest schooling parents: Tertiary & parhistschd3 \\
\hline Mother highest schooling level & mhistsch \\
\hline Father work & fatwork \\
\hline Not employed & fatworkjoblvld 1 \\
\hline Blue collar - low & fatworkjoblvld2 \\
\hline Blue collar - high & fatworkjoblvld3 \\
\hline White collar - low & fatworkjoblvld4 \\
\hline White collar - high & fatworkjoblvld5 \\
\hline Has brothers or sisters & brothsist \\
\hline Mother housewife & mothousewife \\
\hline North West & macroregd 1 \\
\hline North East & macroregd 2 \\
\hline Center & macroregd 3 \\
\hline South & $\operatorname{macroregd} 4$ \\
\hline Islands & macroregd 5 \\
\hline Single & single \\
\hline Lower Secondary grade: low & votomedd1 \\
\hline Lower Secondary grade: medium & votomedd2 \\
\hline Lower Secondary grade: good & votomedd 3 \\
\hline Lower Secondary grade: very good & votomedd 4 \\
\hline Lower secondary and High School grades: & \\
\hline low and low & overallgraded 1 \\
\hline low and medium & overallgraded 2 \\
\hline low and good & overallgraded 3 \\
\hline low and very good & overallgraded 4 \\
\hline medium and low & overallgraded 5 \\
\hline medium and medium & overallgraded 6 \\
\hline medium and good & overallgraded7 \\
\hline medium and very good & overallgraded 8 \\
\hline good and low & overallgraded 9 \\
\hline good and medium & overallgraded 10 \\
\hline good and good & overallgraded 11 \\
\hline good and very good & overallgraded 12 \\
\hline very good and low & overallgraded 13 \\
\hline very good and medium & overallgraded 14 \\
\hline very good and good & overallgraded 15 \\
\hline very good and very good & overallgraded 16 \\
\hline Failed at least once in secondary school & secfailed \\
\hline Secondary school: vocational & trackd1 \\
\hline Secondary school: technical & trackd2 \\
\hline Secondary school: academic & trackd3 \\
\hline
\end{tabular}


Table A.6: Descriptive Statistics of ISTAT sample

\begin{tabular}{|c|c|c|c|c|}
\hline & \multicolumn{2}{|c|}{ Male (mean) } & \multicolumn{2}{|c|}{ Female (mean) } \\
\hline & Basic & Richer & Basic & Richer \\
\hline Never enrolled & 0.6503 & 0.6501 & 0.5567 & 0.5568 \\
\hline Drop-out & 0.0580 & 0.0579 & 0.0525 & 0.0530 \\
\hline Enrolled & 0.2918 & 0.2921 & 0.3908 & 0.3903 \\
\hline parhistschd 1 & 0.5278 & 0.5295 & 0.5649 & 0.5637 \\
\hline parhistschd2 & 0.3820 & 0.3800 & 0.3504 & 0.3509 \\
\hline parhistschd3 & 0.0902 & 0.0905 & 0.0847 & 0.0854 \\
\hline mhistsch & 0.7475 & 0.7473 & 0.7496 & 0.7494 \\
\hline fatwork & 0.9518 & & 0.9451 & \\
\hline fatworkjoblvld1 & & 0.0478 & & 0.0553 \\
\hline fatworkjoblvld2 & & 0.1655 & & 0.1637 \\
\hline fatworkjoblvld3 & & 0.2910 & & 0.3075 \\
\hline fatworkjoblvld4 & & 0.3393 & & 0.3270 \\
\hline fatworkjoblvld5 & & 0.1563 & & 0.1466 \\
\hline brothsist & & 0.8621 & & 0.8675 \\
\hline mothousewife & & 0.5903 & & 0.5788 \\
\hline macroregd1 & 0.2120 & 0.2129 & 0.2430 & 0.2384 \\
\hline macroregd2 & 0.1412 & 0.1417 & 0.1647 & 0.1645 \\
\hline macroregd3 & 0.2123 & 0.2134 & 0.1805 & 0.1842 \\
\hline macroregd 4 & 0.2866 & 0.2834 & 0.2470 & 0.2494 \\
\hline macroregd5 & 0.1479 & 0.1487 & 0.1647 & 0.1636 \\
\hline single & & 0.9752 & & 0.9472 \\
\hline votomedd1 & 0.5300 & & 0.3834 & \\
\hline votomedd2 & 0.2598 & & 0.2907 & \\
\hline votomedd3 & 0.1241 & & 0.1686 & \\
\hline votomedd4 & 0.0860 & & 0.1574 & \\
\hline overallgraded 1 & & 0.3177 & & 0.1917 \\
\hline overallgraded2 & & 0.1573 & & 0.1394 \\
\hline overallgraded3 & & 0.0479 & & 0.0524 \\
\hline overallgraded 4 & & 0.0184 & & 0.0182 \\
\hline overallgraded5 & & 0.0902 & & 0.0735 \\
\hline overallgraded 6 & & 0.0867 & & 0.0934 \\
\hline overallgraded7 & & 0.0518 & & 0.0818 \\
\hline overallgraded 8 & & 0.0256 & & 0.0352 \\
\hline overallgraded9 & & 0.0284 & & 0.0258 \\
\hline overallgraded 10 & & 0.0365 & & 0.0462 \\
\hline overallgraded 11 & & 0.0284 & & 0.0476 \\
\hline overallgraded 12 & & 0.0249 & & 0.0379 \\
\hline overallgraded 13 & & 0.0094 & & 0.0106 \\
\hline overallgraded 14 & & 0.0176 & & 0.0263 \\
\hline overallgraded 15 & & 0.0196 & & 0.0391 \\
\hline overallgraded 16 & & 0.0396 & & 0.0809 \\
\hline secfailed & & 0.2999 & & 0.1832 \\
\hline $\operatorname{trackd} 1$ & 0.4450 & 0.4458 & 0.4395 & 0.4426 \\
\hline $\operatorname{trackd} 2$ & 0.4233 & 0.4241 & 0.3558 & 0.3563 \\
\hline trackd3 & 0.1318 & 0.1301 & $51^{0.2047}$ & 0.2011 \\
\hline $\mathrm{N}$ & 9956 & 10453 & 11527 & 12343 \\
\hline
\end{tabular}


Table A.7a: Sequential Logit - ISTAT - Male

\begin{tabular}{|c|c|c|c|c|c|c|c|c|}
\hline & \multicolumn{4}{|c|}{ Basic } & \multicolumn{4}{|c|}{ Richer } \\
\hline & coef & st err & coef & st err & coef & st err & coef & st err \\
\hline \multicolumn{9}{|l|}{ first choice $\left(\beta^{\prime} s\right)$ : } \\
\hline const & -2.1027 & 0.1384 & -2.2438 & 0.1689 & -2.2202 & 0.2326 & -2.5541 & 0.2428 \\
\hline parhistschd2 & 0.9232 & 0.0522 & 0.6909 & 0.0552 & 0.7728 & 0.0559 & 0.5687 & 0.0596 \\
\hline parhistschd3 & 2.3308 & 0.0961 & 1.6194 & 0.1061 & 1.9353 & 0.1031 & 1.2842 & 0.1145 \\
\hline mhistsch & 0.2320 & 0.0573 & 0.1612 & 0.0603 & 0.184 & 0.0585 & 0.1121 & 0.0621 \\
\hline fatwork & 0.1080 & 0.1174 & 0.0179 & 0.1564 & & & & \\
\hline fatworkjob 2 & & & & & -0.1094 & 0.1292 & -0.0998 & 0.135 \\
\hline fatworkjob 3 & & & & & -0.1601 & 0.1228 & -0.2114 & 0.1286 \\
\hline fatworkjob 4 & & & & & 0.272 & 0.1213 & 0.1559 & 0.1275 \\
\hline fatworkjob 5 & & & & & 0.5307 & 0.1301 & 0.2705 & 0.1377 \\
\hline brothsist & & & & & -0.3066 & 0.0699 & -0.2055 & 0.0749 \\
\hline mothousewife & & & & & -0.2495 & 0.052 & -0.2061 & 0.0553 \\
\hline macroregd 2 & -0.1083 & 0.0817 & -0.0778 & 0.0874 & -0.1523 & 0.0815 & -0.1442 & 0.0874 \\
\hline macroregd3 & -0.0927 & 0.0732 & -0.0420 & 0.0786 & -0.101 & 0.0732 & -0.0594 & 0.0785 \\
\hline macroregd 4 & 0.0438 & 0.0683 & 0.0635 & 0.0727 & 0.1868 & 0.0703 & 0.2022 & 0.0751 \\
\hline macroregd 5 & -0.0961 & 0.0823 & -0.0390 & 0.0863 & 0.0418 & 0.084 & 0.0798 & 0.0884 \\
\hline single & & & & & 0.4136 & 0.1798 & 0.3894 & 0.1839 \\
\hline $\operatorname{trackd} 2$ & & & 0.6867 & 0.0560 & & & 0.8338 & 0.0572 \\
\hline trackd3 & & & 2.7956 & 0.1120 & & & 3.1577 & 0.1151 \\
\hline \multicolumn{9}{|l|}{ Ability: } \\
\hline H.S. grade & Yes & & Yes & & No & & No & \\
\hline Overallgrade & No & & No & & Yes & & Yes & \\
\hline secfailed & & & & & -0.3431 & 0.0569 & -0.4337 & 0.0608 \\
\hline \multicolumn{9}{|l|}{ second choice $\left(\alpha^{\prime} s\right)$ : } \\
\hline const & 1.2119 & 0.2869 & 1.0682 & 0.2915 & 0.7859 & 0.4543 & 0.5828 & 0.4602 \\
\hline parhistschd2 & 0.2964 & 0.1019 & 0.1846 & 0.1035 & 0.2527 & 0.1103 & 0.1533 & 0.1117 \\
\hline parhistschd3 & 1.0347 & 0.1652 & 0.6627 & 0.1735 & 0.9872 & 0.1861 & 0.6332 & 0.1913 \\
\hline mhistsch & -0.0944 & 0.1121 & -0.1208 & 0.1132 & -0.0703 & 0.1131 & -0.0947 & 0.1148 \\
\hline fatwork & -0.2140 & 0.2479 & -0.2692 & 0.2491 & & & & \\
\hline fatworkjob 2 & & & & & -0.2987 & 0.2687 & -0.3027 & 0.2705 \\
\hline fatworkjob 3 & & & & & -0.28 & 0.2566 & -0.2716 & 0.2583 \\
\hline fatworkjob 4 & & & & & -0.1305 & 0.2528 & -0.1671 & 0.2547 \\
\hline fatworkjob 5 & & & & & -0.103 & 0.2673 & -0.231 & 0.2693 \\
\hline brothsist & & & & & 0.159 & 0.1256 & 0.2239 & 0.1276 \\
\hline mothousewife & & & & & -0.0836 & 0.1005 & -0.0353 & 0.1022 \\
\hline macroregd2 & 0.1838 & 0.1662 & 0.2298 & 0.1680 & 0.1252 & 0.1626 & 0.1612 & 0.1651 \\
\hline macroregd3 & -0.1417 & 0.1405 & -0.1176 & 0.1418 & -0.1456 & 0.1389 & -0.1145 & 0.141 \\
\hline macroregd 4 & 0.0973 & 0.1346 & 0.1245 & 0.1356 & 0.1069 & 0.1364 & 0.1418 & 0.1384 \\
\hline macroregd5 & -0.2807 & 0.1545 & -0.2326 & 0.1557 & -0.2911 & 0.1565 & -0.2606 & 0.1581 \\
\hline single & & & & & 0.231 & 0.3415 & 0.096 & 0.3446 \\
\hline $\operatorname{trackd} 2$ & & & 0.3477 & 0.1096 & & & 0.4114 & 0.1099 \\
\hline trackd3 & & & 1.1326 & 0.1604 & & & 1.4283 & 0.1648 \\
\hline \multicolumn{9}{|l|}{ Ability: } \\
\hline H.S. grade & Yes & & Yes & & No & \multicolumn{3}{|c|}{10} \\
\hline \multirow{2}{*}{$\begin{array}{l}\text { Overallgrade } \\
\text { secfailed }\end{array}$} & \multirow[t]{2}{*}{ No } & \multirow{2}{*}{52} & \multirow{2}{*}{\multicolumn{2}{|c|}{ No }} & Yes & \multicolumn{3}{|c|}{ Yes } \\
\hline & & & & & -0.2757 & 0.1112 & -0.3276 & 0.1126 \\
\hline Loglik & -6707 & .97 & -626 & .49 & -681 & .91 & -627 & .32 \\
\hline $\mathrm{N}$ & \multicolumn{4}{|c|}{6} & \multicolumn{4}{|c|}{10453} \\
\hline
\end{tabular}


Table A.7b: Sequential Logit - ISTAT - Female

\begin{tabular}{|c|c|c|c|c|c|c|c|c|}
\hline & \multicolumn{4}{|c|}{ Basic } & \multicolumn{4}{|c|}{ Richer } \\
\hline & coef & st err & coef & st err & coef & st err & coef & st err \\
\hline \multicolumn{9}{|l|}{ first choice $\left(\beta^{\prime} s\right)$ : } \\
\hline const & -1.8132 & 0.1141 & -1.9626 & 0.1206 & -2.2985 & 0.1664 & -2.4686 & 0.1740 \\
\hline parhistschd2 & 0.9330 & 0.0463 & 0.6935 & 0.0493 & 0.7482 & 0.0483 & 0.5612 & 0.0514 \\
\hline parhistschd3 & 2.4834 & 0.1052 & 1.7665 & 0.1134 & 1.9860 & 0.1053 & 1.4111 & 0.1139 \\
\hline mhistsch & 0.2947 & 0.0512 & 0.1939 & 0.0539 & 0.2876 & 0.0511 & 0.2068 & 0.0540 \\
\hline fatwork & 0.0696 & 0.0936 & 0.0183 & 0.0978 & & & & \\
\hline fatworkjob 2 & & & & & -0.1191 & 0.1023 & -0.0824 & 0.1073 \\
\hline fatworkjob 3 & & & & & -0.0682 & 0.0957 & -0.0597 & 0.1003 \\
\hline fatworkjob 4 & & & & & 0.3215 & 0.0958 & 0.2541 & 0.1007 \\
\hline fatworkjob 5 & & & & & 0.6827 & 0.1065 & 0.4975 & 0.1125 \\
\hline brothsist & & & & & -0.3484 & 0.0624 & -0.2738 & 0.0668 \\
\hline mothousewife & & & & & -0.2286 & 0.0449 & -0.1922 & 0.0475 \\
\hline macroregd2 & -0.1677 & 0.0678 & -0.0259 & 0.0723 & -0.1675 & 0.0672 & -0.0554 & 0.0716 \\
\hline macroregd3 & 0.0990 & 0.0654 & 0.2094 & 0.0698 & 0.0830 & 0.0646 & 0.1685 & 0.0692 \\
\hline macroregd 4 & 0.2433 & 0.0606 & 0.3780 & 0.0641 & 0.4156 & 0.0614 & 0.5398 & 0.0651 \\
\hline macroregd 5 & -0.0362 & 0.0687 & 0.0954 & 0.0720 & 0.1540 & 0.0691 & 0.2665 & 0.0731 \\
\hline single & & & & & 0.8015 & 0.1068 & 0.6232 & 0.1085 \\
\hline $\operatorname{trackd} 2$ & & & 0.4891 & 0.0488 & & & 0.5252 & 0.0486 \\
\hline trackd3 & & & 2.3491 & 0.0804 & & & 2.4969 & 0.0812 \\
\hline const & 1.0131 & 0.2332 & 0.9814 & 0.2404 & 0.4002 & 0.3255 & 0.3668 & 0.3301 \\
\hline \multicolumn{9}{|l|}{ Ability: } \\
\hline H.S. grade & Yes & & Yes & & No & & No & \\
\hline Overallgrade & No & & No & & Yes & & Yes & \\
\hline secfailed & & & & & -0.3590 & 0.0585 & -0.4199 & 0.0616 \\
\hline \multicolumn{9}{|l|}{ second choice $\left(\alpha^{\prime} s\right)$ : } \\
\hline parhistschd2 & 0.1541 & 0.0956 & 0.0105 & 0.0981 & 0.1040 & 0.0999 & -0.0118 & 0.1002 \\
\hline parhistschd3 & 0.9845 & 0.1734 & 0.5363 & 0.1810 & 0.9922 & 0.1853 & 0.5966 & 0.1893 \\
\hline mhistsch & 0.2898 & 0.1010 & 0.2327 & 0.1022 & 0.3090 & 0.0997 & 0.2636 & 0.1009 \\
\hline fatwork & 0.1567 & 0.1920 & 0.1314 & 0.1934 & & & & \\
\hline fatworkjob 2 & & & & & 0.1284 & 0.2176 & 0.1487 & 0.2192 \\
\hline fatworkjob 3 & & & & & 0.0966 & 0.2006 & 0.1097 & 0.2019 \\
\hline fatworkjob 4 & & & & & 0.1798 & 0.1971 & 0.1352 & 0.1985 \\
\hline fatworkjob 5 & & & & & 0.2156 & 0.2138 & 0.1137 & 0.2153 \\
\hline brothsist & & & & & -0.2167 & 0.1266 & -0.1558 & 0.1280 \\
\hline mothousewife & & & & & 0.0144 & 0.0903 & 0.0308 & 0.0925 \\
\hline macroregd2 & 0.0140 & 0.1517 & 0.0805 & 0.1501 & 0.0148 & 0.1433 & 0.0561 & 0.1454 \\
\hline macroregd 3 & -0.2346 & 0.1326 & -0.1940 & 0.1337 & -0.2212 & 0.1289 & -0.2084 & 0.1307 \\
\hline macroregd4 & 0.1027 & 0.1301 & 0.2022 & 0.1306 & 0.1679 & 0.1284 & 0.2529 & 0.1296 \\
\hline macroregd 5 & -0.2573 & 0.1412 & -0.1749 & 0.1421 & -0.1605 & 0.1399 & -0.0996 & 0.1412 \\
\hline single & & & & & 0.7647 & 0.2028 & 0.6492 & 0.2048 \\
\hline $\operatorname{trackd} 2$ & & & 0.0464 & 0.1015 & & & 0.0684 & 0.0984 \\
\hline trackd3 & & & 1.1086 & 0.1419 & & & 1.2009 & 0.1391 \\
\hline \multicolumn{9}{|l|}{ Ability: } \\
\hline H.S. grade & Yes & \multirow{3}{*}{53} & \multicolumn{2}{|l|}{ Yes } & No & \multicolumn{3}{|c|}{ No } \\
\hline \multirow{2}{*}{$\begin{array}{l}\text { Overallgrade } \\
\text { secfailed }\end{array}$} & \multirow[t]{2}{*}{ No } & & \multirow{2}{*}{\multicolumn{2}{|c|}{ No }} & Yes & \multicolumn{3}{|c|}{ Yes } \\
\hline & & & & & -0.1465 & 0.1223 & -0.1641 & 0.1234 \\
\hline Loglik & -835 & .27 & -778 & & -873 & .71 & -80 & .68 \\
\hline $\mathrm{N}$ & \multicolumn{4}{|c|}{11527} & \multicolumn{4}{|c|}{12343} \\
\hline
\end{tabular}


Table A.8a: Multinomial Logit - ISTAT - Male

\begin{tabular}{|c|c|c|c|c|c|c|c|c|}
\hline & \multicolumn{4}{|c|}{ Basic } & \multicolumn{4}{|c|}{ Richer } \\
\hline & Coef. & Std. Err. & Coef. & Std. Err. & Coef. & Std. Err. & Coef. & Std. Err. \\
\hline \multicolumn{9}{|l|}{ Drop-out: } \\
\hline parhistschd2 & 0.6976 & 0.0957 & 0.5727 & 0.0973 & 0.5645 & 0.1009 & 0.4594 & 0.1024 \\
\hline parhistschd3 & 1.4614 & 0.1728 & 1.0879 & 0.1805 & 1.0980 & 0.1859 & 0.7853 & 0.1919 \\
\hline mhistsch & 0.2997 & 0.1075 & 0.2636 & 0.1079 & 0.2185 & 0.1071 & 0.1905 & 0.1077 \\
\hline fatwork & 0.2662 & 0.2319 & 0.2212 & 0.2324 & & & & \\
\hline fatworkjob 2 & & & & & 0.1561 & 0.2480 & 0.1509 & 0.2487 \\
\hline fatworkjob 3 & & & & & 0.0569 & 0.2383 & 0.0209 & 0.2390 \\
\hline fatworkjob 4 & & & & & 0.3724 & 0.2356 & 0.3087 & 0.2366 \\
\hline fatworkjob 5 & & & & & 0.6176 & 0.2490 & 0.4813 & 0.2504 \\
\hline brothsist & & & & & -0.4388 & 0.1184 & -0.3816 & 0.1194 \\
\hline mothousewife & & & & & -0.2055 & 0.0937 & -0.1762 & 0.0942 \\
\hline macroregd2 & -0.2214 & 0.1570 & -0.2059 & 0.1577 & -0.2141 & 0.1530 & -0.2088 & 0.1538 \\
\hline macroregd3 & 0.0151 & 0.1321 & 0.0382 & 0.1328 & 0.0258 & 0.1301 & 0.0469 & 0.1310 \\
\hline macroregd 4 & -0.0301 & 0.1273 & -0.0340 & 0.1280 & 0.1161 & 0.1289 & 0.1099 & 0.1297 \\
\hline macroregd5 & 0.1451 & 0.1432 & 0.1412 & 0.1440 & 0.2885 & 0.1444 & 0.2756 & 0.1452 \\
\hline single & & & & & 0.1168 & 0.2934 & 0.1340 & 0.2942 \\
\hline trackd2 & & & 0.4514 & 0.1003 & & & 0.5229 & 0.0994 \\
\hline trackd3 & & & 1.8563 & 0.1776 & & & 1.9875 & 0.1794 \\
\hline $\begin{array}{l}\text { cons. } \\
\text { Ability: }\end{array}$ & -3.5735 & 0.2687 & -3.6584 & 0.2708 & -3.2411 & 0.4036 & -3.4420 & 0.4073 \\
\hline H.S. grade & Yes & & Yes & & No & & No & \\
\hline Overallgrade & No & & No & & Yes & & Yes & \\
\hline $\begin{array}{l}\text { secfailed } \\
\text { Enrolled: }\end{array}$ & \multicolumn{7}{|c|}{ Enrolled: } & 0.1003 \\
\hline parhistschd2 & 0.9855 & 0.0567 & 0.7287 & 0.0601 & 0.8316 & 0.0608 & 0.6055 & 0.0654 \\
\hline parhistschd3 & 2.4993 & 0.0993 & 1.7383 & 0.1102 & 2.1035 & 0.1076 & 1.4051 & 0.1206 \\
\hline mhistsch & 0.2152 & 0.0611 & 0.1335 & 0.0646 & 0.1739 & 0.0627 & 0.0873 & 0.0671 \\
\hline fatwork & 0.0683 & 0.1268 & -0.0381 & 0.1311 & & & & \\
\hline fatworkjob 2 & & & & & -0.1838 & 0.1403 & -0.1762 & 0.1476 \\
\hline fatworkjob 3 & & & & & -0.2191 & 0.1328 & -0.2814 & 0.1401 \\
\hline fatworkjob 4 & & & & & 0.2447 & 0.1306 & 0.1085 & 0.1384 \\
\hline fatworkjob 5 & & & & & 0.5068 & 0.1398 & 0.2076 & 0.1491 \\
\hline brothsist & & & & & -0.2691 & 0.0753 & -0.1490 & 0.0815 \\
\hline mothousewife & & & & & -0.2603 & 0.0561 & -0.2164 & 0.0601 \\
\hline macroregd2 & -0.0812 & 0.0876 & -0.0438 & 0.0938 & -0.1382 & 0.0873 & -0.1264 & 0.0945 \\
\hline macroregd3 & -0.1210 & 0.0790 & -0.0665 & 0.0845 & -0.1351 & 0.0789 & -0.0926 & 0.0854 \\
\hline macroregd 4 & 0.0620 & 0.0733 & 0.0895 & 0.0780 & 0.2041 & 0.0754 & 0.2286 & 0.0812 \\
\hline macroregd5 & -0.1675 & 0.0897 & -0.0966 & 0.0939 & -0.0361 & 0.0917 & 0.0123 & 0.0970 \\
\hline single & & & & & 0.5212 & 0.2057 & 0.4917 & 0.2114 \\
\hline trackd2 & & & 0.7654 & 0.0625 & & & 0.9391 & 0.0640 \\
\hline trackd3 & & & 2.9745 & 0.1153 & & & 3.4255 & 0.1200 \\
\hline \multicolumn{8}{|l|}{ Ability: } & 0.2739 \\
\hline H.S. grade & \multirow{3}{*}{$\begin{array}{l}\text { Yes } \\
\text { No }\end{array}$} & & Yes & & No & & No & \\
\hline \multirow{2}{*}{$\begin{array}{l}\text { Overallgrade } \\
\text { secfailed }\end{array}$} & & \multirow{2}{*}{\multicolumn{2}{|c|}{$54^{\text {No }}$}} & & Yes & & Yes & \\
\hline & & & & & -0.4073 & 0.0629 & -0.5167 & 0.0679 \\
\hline $\mathrm{N}$ & \multicolumn{4}{|c|}{9956} & \multicolumn{4}{|c|}{10453} \\
\hline Loglik & \multicolumn{2}{|c|}{-6707.41} & \multicolumn{2}{|c|}{-6270.86} & \multicolumn{2}{|c|}{-6812.41} & \multicolumn{2}{|c|}{-6269.72} \\
\hline
\end{tabular}


Table A.8b: Multinomial Logit - ISTAT - Female

\begin{tabular}{|c|c|c|c|c|c|c|c|c|}
\hline & \multicolumn{4}{|c|}{ Basic } & \multicolumn{4}{|c|}{ Richer } \\
\hline & Coef. & Std. Err. & Coef. & Std. Err. & Coef. & Std. Err. & Coef. & Std. Err \\
\hline \multicolumn{9}{|l|}{ Drop-out: } \\
\hline parhistschd2 & 0.7803 & 0.0940 & 0.6751 & 0.0952 & 0.6552 & 0.0964 & 0.5781 & 0.0972 \\
\hline parhistschd3 & 1.5894 & 0.1905 & 1.2817 & 0.1965 & 1.1219 & 0.1960 & 0.9052 & 0.1998 \\
\hline mhistsch & 0.0507 & 0.0996 & 0.0086 & 0.1000 & 0.0420 & 0.0977 & 0.0101 & 0.0982 \\
\hline fatwork & -0.0700 & 0.1845 & -0.0889 & 0.1849 & & & & \\
\hline fatworkjob 2 & & & & & -0.2366 & 0.2067 & -0.2152 & 0.2073 \\
\hline fatworkjob 3 & & & & & -0.1699 & 0.1910 & -0.1745 & 0.1915 \\
\hline fatworkjob 4 & & & & & 0.1564 & 0.1890 & 0.1255 & 0.1897 \\
\hline fatworkjob 5 & & & & & 0.4716 & 0.2067 & 0.3933 & 0.2076 \\
\hline brothsist & & & & & -0.1719 & 0.1253 & -0.1388 & 0.1260 \\
\hline mothousewife & & & & & -0.2084 & 0.0892 & -0.1896 & 0.0896 \\
\hline macroregd 2 & -0.1822 & 0.1443 & -0.1018 & 0.1451 & -0.1704 & 0.1394 & -0.1113 & 0.1401 \\
\hline macroregd 3 & 0.2922 & 0.1288 & 0.3532 & 0.1295 & 0.2638 & 0.1253 & 0.3201 & 0.1261 \\
\hline macroregd4 & 0.1605 & 0.1268 & 0.2006 & 0.1274 & 0.2630 & 0.1257 & 0.3017 & 0.1264 \\
\hline macroregd5 & 0.1935 & 0.1356 & 0.2420 & 0.1363 & 0.2980 & 0.1350 & 0.3419 & 0.1357 \\
\hline single & & & & & 0.0951 & 0.1769 & 0.0409 & 0.1773 \\
\hline trackd2 & & & 0.4820 & 0.0971 & & & 0.4614 & 0.0940 \\
\hline trackd3 & & & 1.3670 & 0.1506 & & & 1.4144 & 0.1479 \\
\hline const & -3.0909 & 0.2244 & -3.2400 & 0.2281 & -3.0189 & 0.3064 & -3.1804 & 0.3098 \\
\hline \multicolumn{9}{|l|}{ Ability: } \\
\hline H.S. grade & Yes & & Yes & & No & & No & \\
\hline Overallgrade & No & & No & & Yes & & Yes & \\
\hline secfailed & & & & & -0.2339 & 0.1143 & -0.2888 & 0.1149 \\
\hline \multicolumn{9}{|l|}{ Enrolled: } \\
\hline parhistschd2 & 0.9585 & 0.0484 & 0.6971 & 0.0519 & 0.7637 & 0.0506 & 0.5575 & 0.0542 \\
\hline parhistschd3 & 2.5937 & 0.1067 & 1.8383 & 0.1156 & 2.0962 & 0.1075 & 1.4913 & 0.1169 \\
\hline mhistsch & 0.3366 & 0.0536 & 0.2316 & 0.0568 & 0.3315 & 0.0536 & 0.2489 & 0.0570 \\
\hline fatwork & 0.0951 & 0.0983 & 0.0407 & 0.1028 & & & & \\
\hline fatworkjob 2 & & & & & -0.0974 & 0.1080 & -0.0551 & 0.1141 \\
\hline fatworkjob 3 & & & & & -0.0498 & 0.1010 & -0.0360 & 0.1067 \\
\hline fatworkjob 4 & & & & & 0.3514 & 0.1008 & 0.2809 & 0.1069 \\
\hline fatworkjob 5 & & & & & 0.7217 & 0.1116 & 0.5209 & 0.1189 \\
\hline brothsist & & & & & -0.3785 & 0.0648 & -0.3009 & 0.0698 \\
\hline mothousewife & & & & & -0.2314 & 0.0470 & -0.1923 & 0.0501 \\
\hline macroregd2 & -0.1660 & 0.0708 & -0.0116 & 0.0762 & -0.1669 & 0.0702 & -0.0437 & 0.0755 \\
\hline macroregd 3 & 0.0632 & 0.0685 & 0.1775 & 0.0736 & 0.0499 & 0.0676 & 0.1345 & 0.0731 \\
\hline macroregd 4 & 0.2549 & 0.0630 & 0.4098 & 0.0671 & 0.4409 & 0.0639 & 0.5859 & 0.0684 \\
\hline macroregd 5 & -0.0804 & 0.0718 & 0.0648 & 0.0762 & 0.1258 & 0.0727 & 0.2500 & 0.0774 \\
\hline single & & & & & 0.9936 & 0.1203 & 0.7982 & 0.1229 \\
\hline trackd2 & & & 0.4924 & 0.0521 & & & 0.5403 & 0.0519 \\
\hline trackd3 & & & 2.4587 & 0.0819 & & & 2.6367 & 0.0832 \\
\hline const & -2.0948 & 0.1202 & -2.2568 & 0.1277 & -2.7559 & 0.1809 & -2.9467 & 0.1903 \\
\hline \multicolumn{9}{|l|}{ Ability: } \\
\hline H.S. grade & Yes & & Yes & & No & & No & \\
\hline \multirow{2}{*}{$\begin{array}{l}\text { Overallgrade } \\
\text { secfailed }\end{array}$} & No & & No & & Yes & & Yes & \\
\hline & & & 5 & & -0.3854 & 0.0627 & -0.4500 & 0.0664 \\
\hline Loglik & \multicolumn{2}{|c|}{-8350.55} & \multicolumn{2}{|c|}{-7780.80} & \multicolumn{2}{|c|}{-8728.85} & \multicolumn{2}{|c|}{-8090.60} \\
\hline $\mathrm{N}$ & \multicolumn{4}{|c|}{11527} & \multicolumn{4}{|c|}{12343} \\
\hline
\end{tabular}


Table A.9: Descriptive Statistics GSOEP Sample

\begin{tabular}{lcc}
\hline & Male (Means) & Female (Means) \\
\hline Dependent Var: & & \\
Enrolled University & 0.343 & 0.365 \\
Enrolled Vocational & 0.585 & 0.588 \\
Never Enrolled & 0.072 & 0.047 \\
& & \\
age & 24.351 & 24.176 \\
single & 0.791 & 0.725 \\
Parents Secondary School & & \\
Academic & 0.311 & 0.315 \\
Technical & 0.413 & 0.360 \\
Vocational & 0.276 & 0.325 \\
Grade in Math: & & \\
1 & 0.180 & 0.129 \\
2 & 0.359 & 0.372 \\
3 & 0.303 & 0.325 \\
4 & 0.158 & 0.174 \\
Secondary School Track: & & \\
realschule & 0.418 & 0.362 \\
fachhochschule & 0.080 & 0.075 \\
abitur & 0.469 & 0.496 \\
other degree & 0.032 & 0.066 \\
N & 373 & \\
\hline & & \\
\end{tabular}


Table A.10a: Multinomial Logit - GSOEP - Male

\begin{tabular}{lcccc}
\hline & Coef. & Std. Err. & Coef. & Std. Err. \\
\hline Enrolled University: & & & & \\
age & 0.2943 & 0.0937 & 0.2319 & 0.1033 \\
single & 0.1102 & 0.6065 & -0.2222 & 0.6428 \\
parents: academic & -0.1969 & 0.6068 & -0.6114 & 0.7014 \\
parents: technical & 0.6156 & 0.7077 & 0.3767 & 0.7883 \\
grademath=1 & 2.2935 & 0.7574 & 2.3311 & 0.7701 \\
grademath=2 & 1.0761 & 0.5733 & 1.2548 & 0.5929 \\
grademath=3 & 1.6600 & 0.7119 & 1.8236 & 0.7209 \\
track: Realschule & & & -2.7900 & 1.1760 \\
track: Abitur & & & 0.1370 & 0.9006 \\
track: Other & & & -0.8413 & 1.2189 \\
cons & -6.9058 & 2.4741 & -4.7417 & 2.8456 \\
Enrolled Vocational: & & & & \\
age & 0.1347 & 0.0918 & 0.2473 & 0.1027 \\
single & 0.3373 & 0.5878 & 0.3543 & 0.6390 \\
parents: academic & -2.0166 & 0.5791 & -1.5315 & 0.6628 \\
parents: technical & 0.3592 & 0.6647 & 0.5239 & 0.7419 \\
grademath=1 & 0.5235 & 0.7658 & 0.6345 & 0.8125 \\
grademath=2 & 0.6226 & 0.5371 & 0.3428 & 0.5771 \\
grademath=3 & 1.8833 & 0.6737 & 1.7070 & 0.7054 \\
track: Realschule & & & 1.0470 & 0.9347 \\
track: Abitur & & & -0.9074 & 0.8903 \\
track: Other & & & -1.4802 & 1.2414 \\
cons & -1.5005 & 2.3800 & -4.2992 & 2.8237 \\
& & & & \\
Loglik & -266.45 & & -202.43 & \\
N & 373 & & 373 & \\
\hline \hline
\end{tabular}


Table A.10b: Multinomial Logit - GSOEP - Female

\begin{tabular}{lcccc}
\hline & Coef. & Std. Err. & Coef. & Std. Err. \\
\hline Enrolled University: & & & & \\
age & 0.2484 & 0.0943 & 0.1753 & 0.1025 \\
single & 1.6828 & 0.5307 & 1.1915 & 0.6072 \\
parents: academic & 0.9838 & 0.6143 & 0.0457 & 0.6900 \\
parents: technical & 0.9191 & 0.6344 & 0.4590 & 0.6919 \\
grademath=1 & 0.4901 & 0.9664 & 1.1041 & 1.0651 \\
grademath=2 & -0.5467 & 0.7196 & -0.1730 & 0.7801 \\
grademath=3 & -0.1545 & 0.7958 & 0.3047 & 0.8577 \\
track: Realschule & & & -18.9672 & 2.7454 \\
track: Abitur & & & -15.5036 & 2.7923 \\
track: Other & & & -18.0230 & 2.7509 \\
cons & -5.5383 & 2.5129 & 13.3529 & \\
Enrolled Vocational: & & & & \\
age & 0.1000 & 0.0914 & 0.0931 & 0.0984 \\
single & 1.5200 & 0.5080 & 0.8958 & 0.5790 \\
parents: academic & -1.1549 & 0.5937 & -1.4786 & 0.6681 \\
parents: technical & 0.1773 & 0.5932 & -0.2116 & 0.6532 \\
grademath=1 & -0.5803 & 0.9757 & 0.1378 & 1.0645 \\
grademath=2 & -0.4736 & 0.7045 & -0.0015 & 0.7448 \\
grademath=3 & 0.3939 & 0.7753 & 0.8228 & 0.8205 \\
track: Realschule & & & -16.7331 & 2.7593 \\
track: Abitur & & & -16.6701 & 2.8276 \\
track: Other & & & -19.4397 & 2.7861 \\
cons & -0.3765 & 2.4116 & 17.0707 & 1.4524 \\
& & & & \\
Loglik & -292.90 & & -235.92 & \\
N & 425 & & 425 & \\
\hline \hline
\end{tabular}



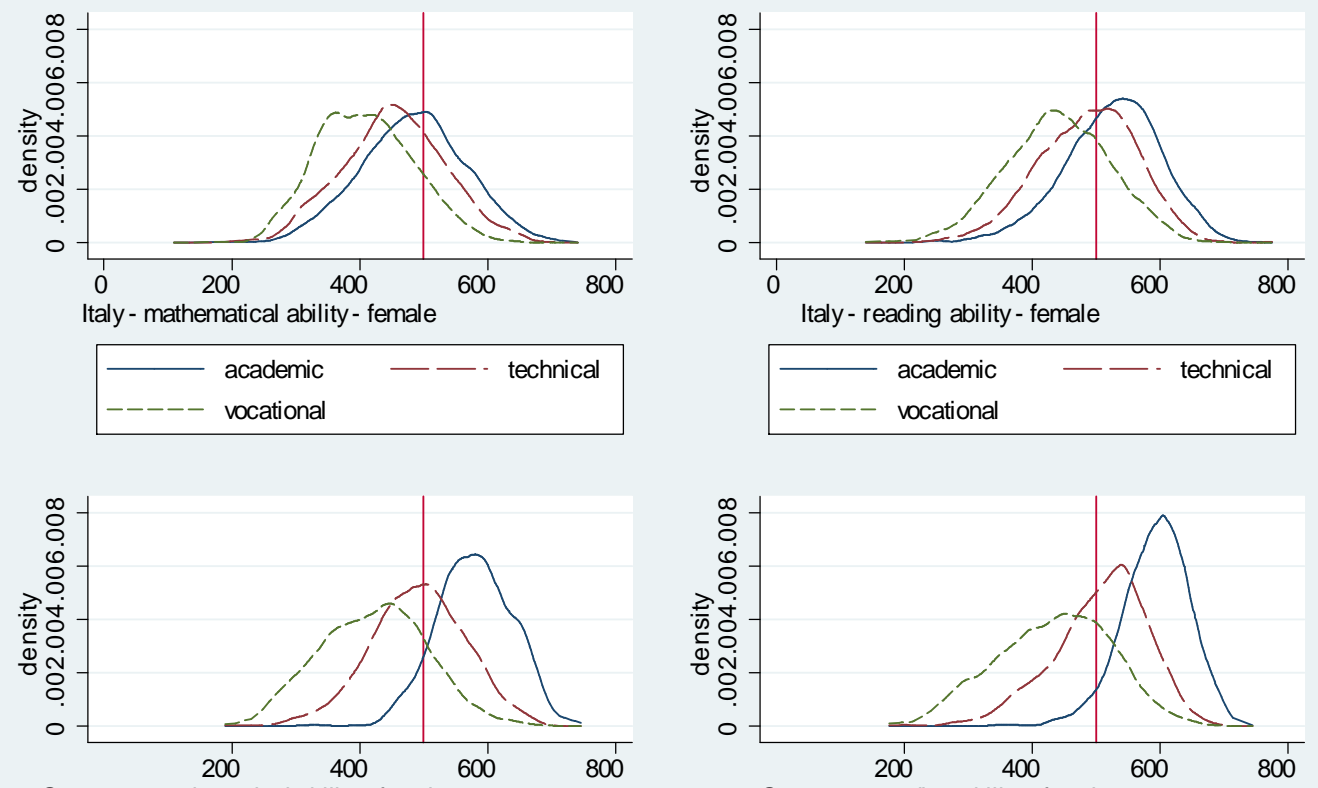

Germany - mathematical ability - female

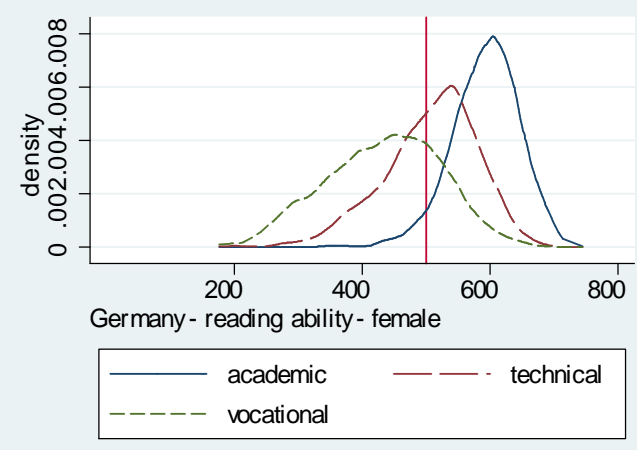

Figure 1: Kernel density estimates of the distribution of mathematical and reading abilities - females - PISA 2003 

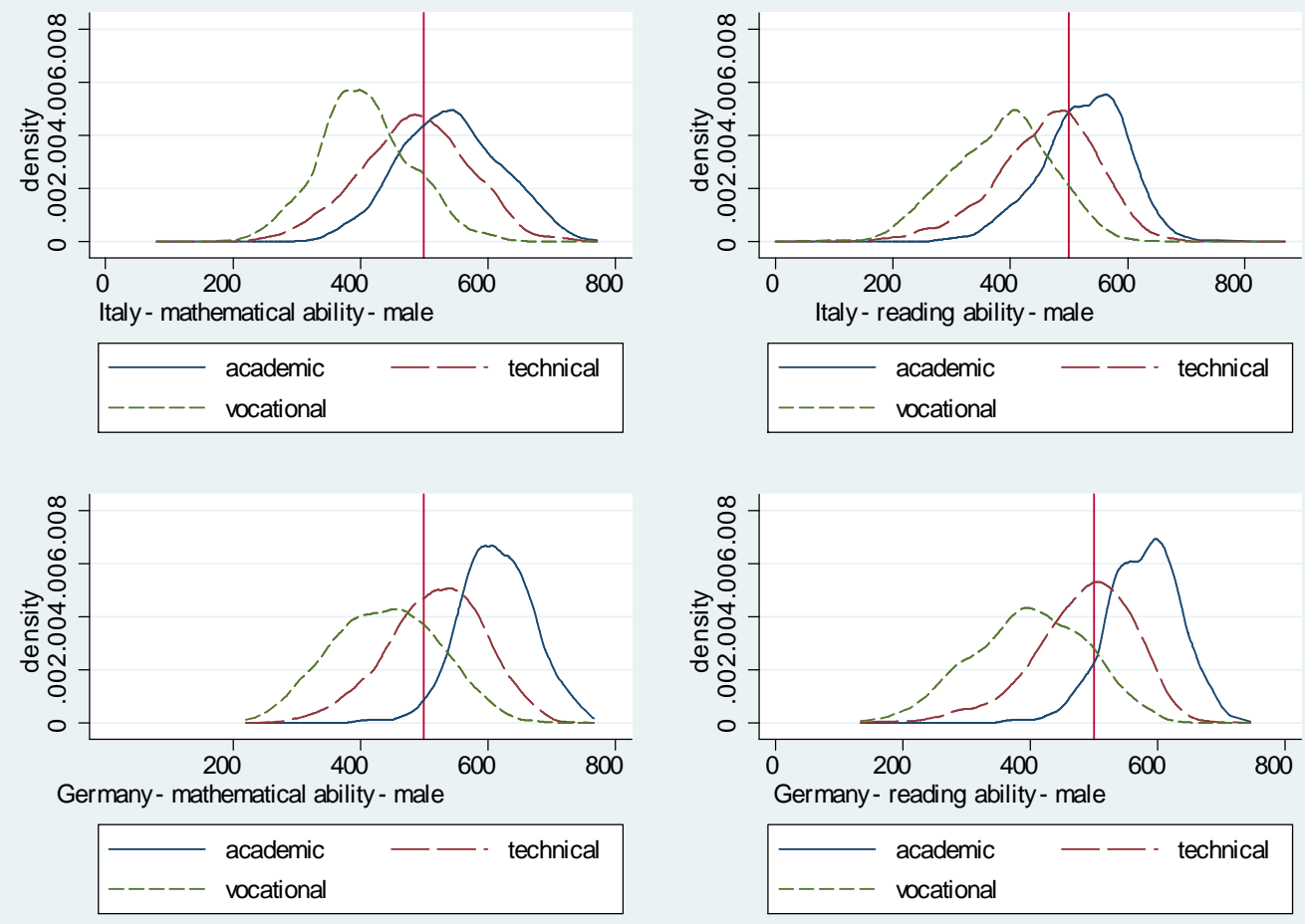

Figure 2: Kernel density estimates of the distribution of mathematical and reading abilities - males - PISA 2003 

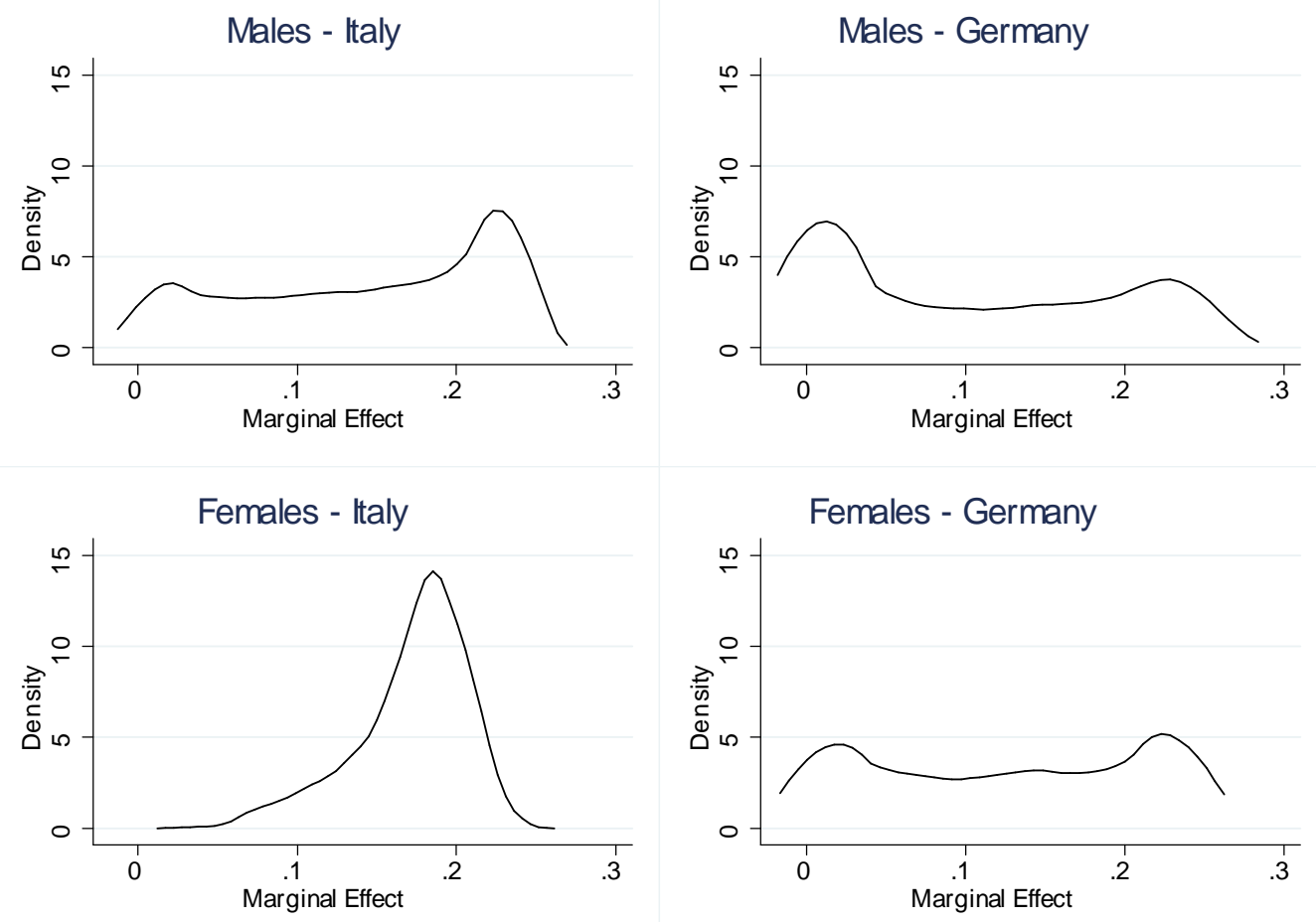

Figure 3: Density Estimation of the Distribution of Marginal Effects of at least one Parent with College on the Academic Track Choice 

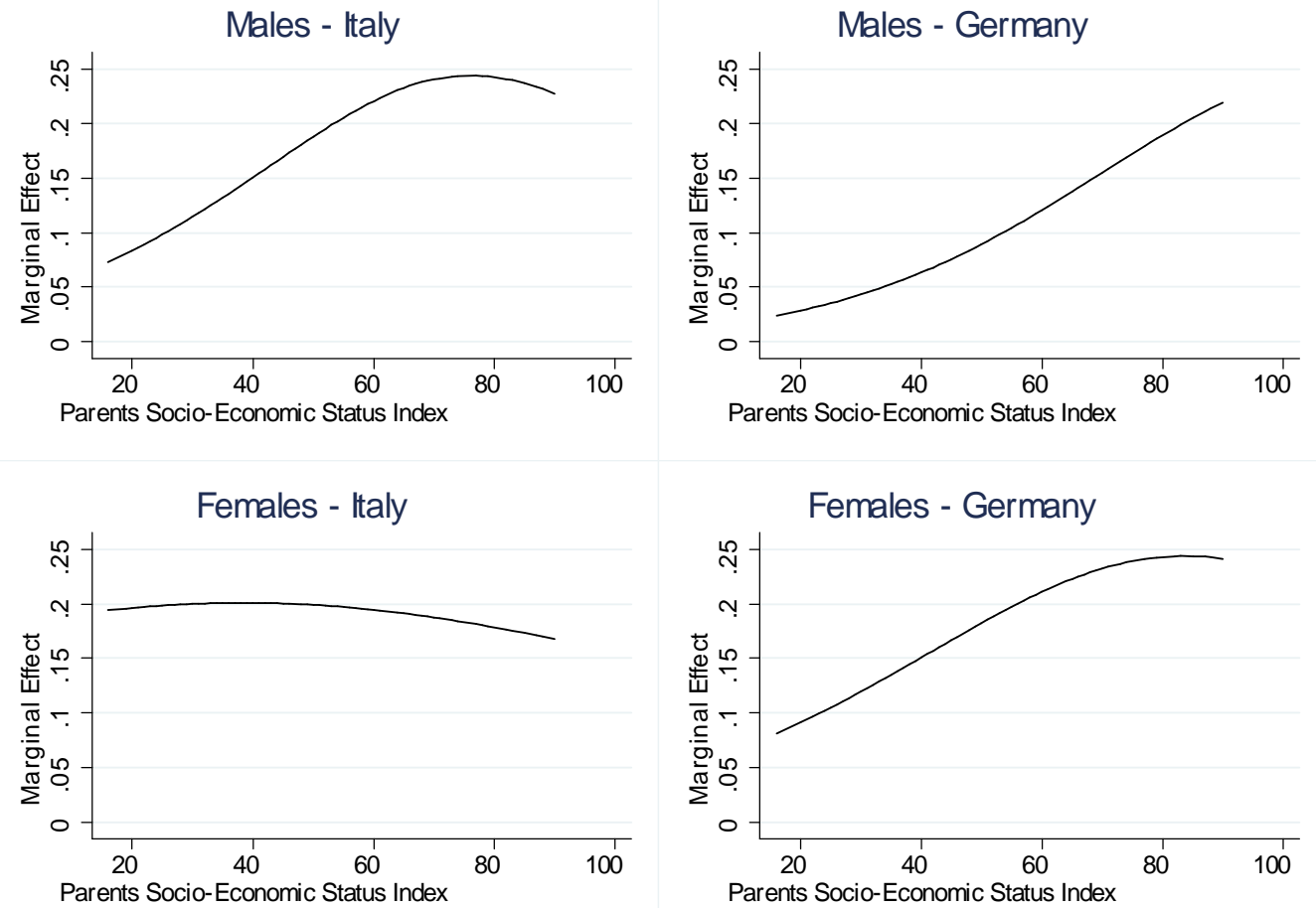

Figure 4: Counterfactual Marginal Effects of at least one Parent with College on the Academic Track Choice by Parents Socio-Economic Status Index 

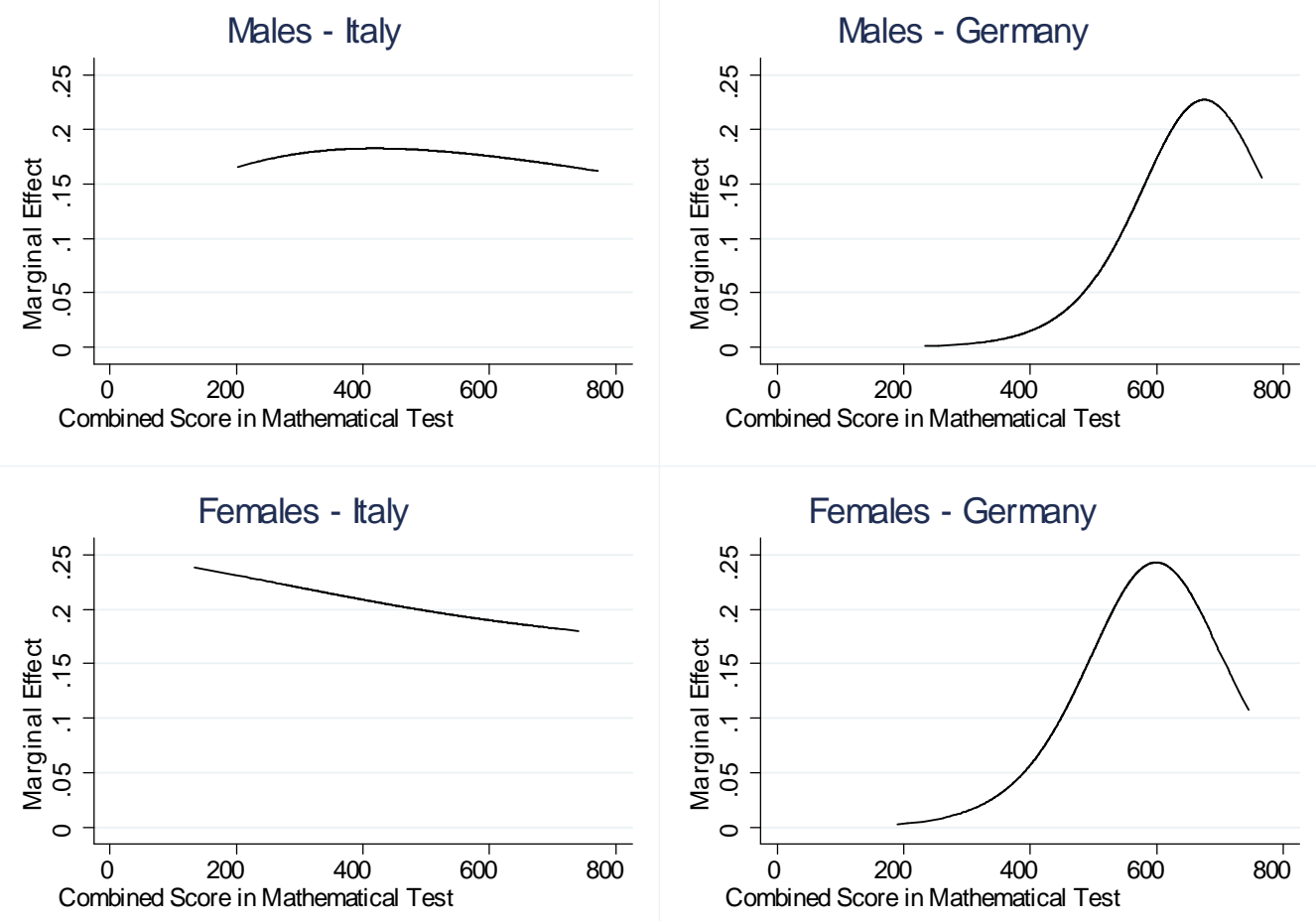

Figure 5: Counterfactual Marginal Effects of at least one Parent with College on the Academic Track Choice by Combined Score in Mathematical Test 